Review Article

\title{
Cancer Etiology: A Metabolic Disease Originating from Life's Major Evolutionary Transition?
}

\author{
B. Poljsak $\mathbb{D}^{1},{ }^{1}$ V. Kovac, ${ }^{1}$ R. Dahmane $\mathbb{D}^{2},{ }^{2}$ T. Levec, $^{3}$ and A. Starc $\mathbb{D}^{3}$ \\ ${ }^{1}$ Faculty of Health Sciences, University of Ljubljana, Laboratory of Oxidative Stress Research, Ljubljana, Slovenia \\ ${ }^{2}$ Faculty of Health Sciences, University of Ljubljana, Chair of Biomedicine in Health Care, Ljubljana, Slovenia \\ ${ }^{3}$ Faculty of Health Sciences, University of Ljubljana, Chair of Public Health, Ljubljana, Slovenia
}

Correspondence should be addressed to A. Starc; andrej.starc@guest.arnes.si

Received 17 March 2019; Revised 21 July 2019; Accepted 27 August 2019; Published 8 October 2019

Academic Editor: Cinzia Domenicotti

Copyright $\odot 2019$ B. Poljsak et al. This is an open access article distributed under the Creative Commons Attribution License, which permits unrestricted use, distribution, and reproduction in any medium, provided the original work is properly cited.

\begin{abstract}
A clear understanding of the origins of cancer is the basis of successful strategies for effective cancer prevention and management. The origin of cancer at the molecular and cellular levels is not well understood. Is the primary cause of the origin of cancer the genomic instability or impaired energy metabolism? An attempt was made to present cancer etiology originating from life's major evolutionary transition. The first evolutionary transition went from simple to complex cells when eukaryotic cells with glycolytic energy production merged with the oxidative mitochondrion (The Endosymbiosis Theory first proposed by Lynn Margulis in the 1960s). The second transition went from single-celled to multicellular organisms once the cells obtained mitochondria, which enabled them to obtain a higher amount of energy. Evidence will be presented that these two transitions, as well as the decline of NAD+ and ATP levels, are the root of cancer diseases. Restoring redox homeostasis and reactivation of mitochondrial oxidative metabolism are important factors in cancer prevention.
\end{abstract}

\section{Introduction}

Could cancer causation be interpreted as an allegory not to the damaged hardware (damaged genetic material caused by chance mutation) but to an incorrect function of a software (a metabolic program)? Do we thence use wrong approaches to treat the cancer disease with chemotherapy and radiation therapy, which are aimed at destroying the hardware (killing cells), instead of a more sophisticated approach aimed at reprogramming the software inside the cells in order to restore the normal mitochondrial function and metabolism?

There are carcinogenic and tumorigenic cells with zero mutations [1], and there are many somatic mutations in cancer-driver genes in healthy tissue, which does not become a cancer [2], with so-called driver mutations [3]. Furthermore, experiments on the nucleus and mitochondrial transfer revealed that tumorigenic phenotype is upgraded when tumor mitochondria are transferred to a normal cell cytoplasm and vice versa. This can be illustrated by the transplantation of noncancerous mitochondria which can inhibit tumor properties of metastatic cells [4-9]. Additionally, tumorigenesis may be suppressed by normal mitochondrial function [10-12], and metabolic enzymes of the Krebs cycle have been recognized as oncosuppressors [13].

Both abnormalities in tumor suppressor genes (antioncogene acting to inhibit cell proliferation and tumor development) and oncogenes can be caused by impaired mitochondrial function [14]. Aerobic glycolysis of tumors is in some measure displayed by activation of oncogenes or absence of tumor suppressors, which are then additionally intensified by stabilization of the hypoxia-inducible factor (HIF) [15], which encodes for all of the glycolytic enzymes. It seems that fully operating mitochondria regulate apoptosis by releasing cytochrome $c$ [16] and suppressing genes of cancer-like metabolism, which have been conserved from 500,000 million years ago and persist in cells of multicellular organisms. Such a program, which enables the development of cancer, preexists in genes in the nucleus from the season of low $\mathrm{O}_{2}$ atmosphere and single-celled life. Namely, cancer cells shift their metabolism toward glycolysis, a strategy that allows for their survival when oxygen is limited [17], and 
consequently increase the availability of biosynthetic intermediates needed for cellular growth and proliferation [18]. $\mathrm{Du}$ [19] proposed a hypothesis that "the survival style of cancer cells was the reevolution from eukaryotic to prokaryotic cells by the alteration of energy metabolism." A human body is a sum of colonies of cells and their mitochondria. The cells composing the human body are similar to singlecelled eukaryotes (existing 500,000 million years ago) although human cells can no longer survive on their own and generally do not use the primitive source of energy, e.g., substrate-level phosphorylation, to produce ATP. The first life emerged on Earth around 3.5 billion years ago, when the early biosphere was more reduced. The increased amounts of dioxygen $\left(\mathrm{O}_{2}\right)$ emerged approximately 2.4 billion years ago when cyanobacteria, as a product of oxygenic photosynthesis, triggered the "Great Oxidation Event" [20]. Due to the elevated $\mathrm{O}_{2}$ in the atmosphere, methods of mitigating its toxicity inside cells had to evolve [21], and the existing metabolic pathways had to be reshaped in early aerobic organisms, which adapted to use $\mathrm{O}_{2}$ as a high-potential redox couple. Multicellular life appeared more than a billion-and-ahalf years ago, and the Cambrian explosion (somewhere around 542 million years ago) resulted in the divergence of major animal groups. Both metabolic transitions have allowed divergence of life forms on Earth, but evolution has not provided a way to prevent the onset of cancer. Since the entire history of humanity, with the exception in the last 100 years, the average lifespan was between 20 and 30 years; consequently, there might not be much evolutionary pressure to eradicate cancer as a disease of mostly elderly persons.

1.1. Somatic Mutation Theory vs. Metabolic Impairment Theory/Mitochondrial Theory of Cancer. At present, cancer is regarded a genetic disease arising from numerous mutations in oncogenes and tumor suppressor genes. Are gene mutations in the cell nucleus the causal event in the origin of cancer (as suggested by the somatic mutation theory) or is the damaged genetic material just the consequence and not the primary cause of cancer? Is cancer caused by damaged mitochondria (impaired mitochondrial function) and metabolic dysfunction, which activates the divergence of the glucose metabolism away from the energy production and stimulates cell growth (transition from oxidative phosphorylation to glycolysis/fermentation)? Is it genomic instability or debilitated energy metabolism that is essentially in charge of the cause of cancer? While tumor growth could be explained by the classical multistage model of carcinogenesis, the model does not provide rationale for the beginning of tumor development [22]. In the last 50 years, it has been accepted that initiation is the one event during which one or more mutations transform a normal somatic cell into a latent neoplastic cell, that is, a tumor cell still lacking multiplicative autonomy. This phase is then followed by promotion in which further mutations and proliferative stimuli induce the initiated cell to give rise to the progeny constituting the tumor. However, it remains to be elucidated what is the effect and what is the cause of normal-to-tumor cell transformation. Cancer was primarily considered as a type of somatic genetic disease in accordance with Boveri's cancer theory $[23,24]$ where harm to a cell's nuclear DNA underlies the change of a normal cell into a cancer cell [25-27]. Indeed, multiple and heterogeneous mutations are found in cancer cells [22]. The question however remains whether DNA mutations are the initiating event causing cancer or are they merely necessary contributors to the progression of tumor after its initiation? Are we battling cancer from the right front considering the hypothesis that DNA mutations as drivers are not that significant in initiation of tumors? Can tumors arise with regular division and mutation rates? Namely, spontaneous mutations are of the order $10^{-5}$ [28]. Estimated probability of mutating five genes, such as both alleles of a particular tumor suppressor gene and an oncogene, is $10^{-20}$ [29]. Thus, in terms of genetic hits in one cell, it is difficult to explain cancer formation as a result of the acquirement of random genetic mutations.

On the other hand, Seyfried et al. [27] explain cancer as essentially a metabolic disease related to disturbances in energy production through respiration and fermentation. According to the metabolic impairment theory/mitochondrial theory of cancer $[4,27,30-34]$, cancer can best be explained as a class/kind of mitochondrial disease. As indicated by Warburg's hypothesis, cancer cells emerge from normal body cells through steady and irreversible harm to their respiratory capacity. Just those body cells which are able to increase glycolysis during intermittent respiratory damage are viewed as fit for forming cancers [31, 32]. The gene theory of cancer suggests that dysfunctional mitochondria could be the resultative and not the causative factor of cancers. On the other hand, the metabolic impairment theory indicates the contrary. Abnormal energy metabolism characterises most tumor cells in all types of tissues [14]. It was further observed that genes for glycolysis are excessively expressed in the major part of cancers explored into $[35,36]$. What is more, the cancer cell metabolism is regulated also by metabolic oncogenes and tumor suppressor genes (e.g., K-ras, p53, PI3K, Akt, and MYC) which have evolved to regulate the Warburg effect [37]. Several studies indicate that the structure and function of tumor mitochondria are not normal and as such not capable to generate the adequate levels of energy [38-47]. The mitochondrial structure is intimately related to mitochondrial function. Abnormalities in both the content and composition of mitochondria have been observed in different tumor tissues in vivo. On the contrary, in different human and animal tumor cells, when they are grown in the in vitro conditions, in contrast to structural defects, reduced numbers or the absence of mitochondria is commonly not observed [27]. Moreover, some researchers observed that in different tumor types, mitochondria and OXPHOS are normal. However, such results were noticed mainly from the in vitro studies measuring oxygen consumption rates in tumor cells [48-53]. Already half a century ago, Warburg suggested that oxygen consumption could be comparable in normal and tumor cells although ATP formation is significantly lesser in tumor cells. The fact that the oxygen consumption rate can be similar or even greater in cultured tumor cells than in nontumorigenic cells was claimed also by different other authors $[40,54,55]$. However, it has been established that the oxygen consumption rate alone cannot 


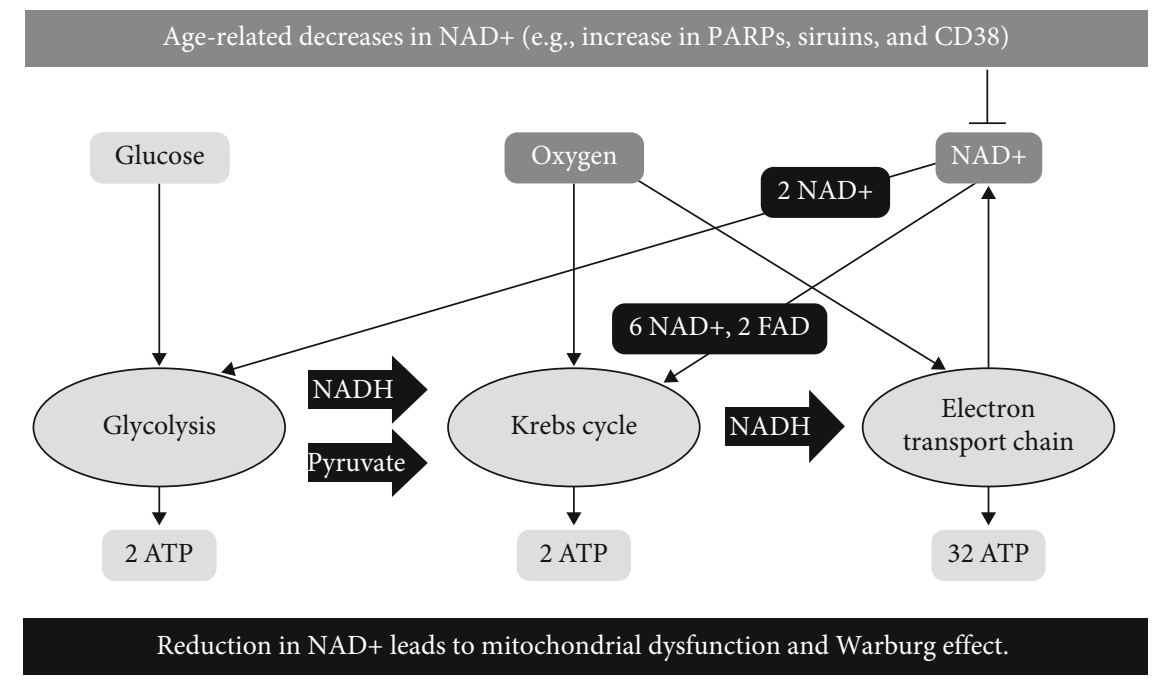

FIgURE 1: $\mathrm{O}_{2}$ and NAD+ as limiting factors in driving oxidative phosphorylation. The figure presents a hypothesis that in situations with limited availability of NAD+, the cells will activate the program which switches off Krebs cycle and electron transport chain (process consumes $6 \mathrm{NAD}+$ ) and favors glycolysis (process consumes $2 \mathrm{NAD}+$ ) in order to obtain energy, preserve NAD+, and avoid cell death through reduced ATP production and activation of apoptosis. *Abbreviations: PARP: poly(adenosine diphosphate [ADP] ribose) polymerases; CD38: NAD+ glycohydrolases; sirtuins: NAD-dependent histone deacetylase ("HDAC") enzymes.

be considered as an indicator of coupled respiration. This can be explained by the fact that some tumor cells consume oxygen while the glycolytically derived ATP is imported and hydrolysed through the mitochondrial adenine nucleotide transporter 2 so as to preserve the proton motive gradient [56]. Moreover, the cultured cell lines are usually derived from only a single cell or a few cells of a heterogeneous tumor. It can be concluded that mitochondria might appear functionally normal in many types of cultured tumor cells but appear structurally abnormal when evaluated in the tumor cells of many primary malignant cancers.

1.2. Mitochondrial Substrate-Level Phosphorylation (mSLP) Provides Energy Source for Cancer Cells: The Missing Link in Warburg's Theory. Reduced ATP formation through impaired oxidative phosphorylation or hypoxia must be compensated by tumor cells with an alternative source of energy. Glucose and glutamine represent available fermentable fuels, since acetate and branched chain amino acids are not present in adequate quantities and other amino acids can be used only with the presence of high-energy phosphates for the metabolic conversion to succinyl-CoA, which is the substrate for MSLP [57]. MSLP produces highenergy phosphates through glutaminolysis and represents a compensatory energy mechanism for cancer cells with insufficient or defective OXPHOS [58]. According to Seyfried et al. $[57,58]$, the missing link in Warburg's theory is the succinic acid fermentation which uses glutamine as a major substrate through sequential conversion of glutamine $\rightarrow$ glutamate $\rightarrow$ alpha-ketoglutarate $\rightarrow$ succinyl-CoA $\rightarrow$ succinate.

1.3. Deficiency of Energy: From Respiration to Fermentation. In order to enable multicellular life, cells must adapt to strict control of cell division and differentiation. Such cooperation works until there is enough energy supply in the form of
NAD+ and ATP. However, both NAD+ levels and energy production in the form of ATP decline with age [59-61], and the incidence of many types of cancer increases with aging $[62,63]$.

Age-related decline of NAD+ leads to mitochondrial dysfunction (Figure 1), which leads to the Warburg effect [64]. $\mathrm{NAD}+$ or $\mathrm{NAD}+/ \mathrm{NADH}$ ratio can have an impact on the frequency of DNA mutation, epigenetic changes in DNA, and also metabolic programming [65]. The role of NAD+ is in accepting hydride equivalents, from glycolytic and TCA cycle metabolites, to form reduced $\mathrm{NADH}$, which enables mitochondrial electron transport chain (ETC) to fuel oxidative phosphorylation [66]. In addition, high NAD+ levels regulate SIRT activity which influences metabolism, DNA repair, stress resistance, cell survival, inflammation, mitochondrial function, and lipid and glucose homeostasis, by targeting FOXO, PGC- $1 \alpha$, p $53, \mathrm{NF}-\kappa \mathrm{B}, \mathrm{HIF}-1 \alpha$, and many other cellular targets [65].

According to Warburg's theory of cancer, the energy through fermentation gradually compensates for insufficient respiration $[31,67]$ which allows a cell to stay alive. NAD+ content is a basic protective factor at the beginning of carcinogenesis, and decreased NAD+ intracellular concentration might play a significant role in the process of cancer development by limiting energy production which negatively affects genomic stability by altering responses to stress and efficiency of the DNA repair $[65,68]$.

1.4. Potential Protumorigenic Side Effects of Increased NAD+. $\mathrm{NAD}+$ can act as both pro- and antitumorigenic due to its mediated reactions on the mechanism of apoptotic cell death and inflammation. Different inflammatory soluble molecules secreted by senescent cells that could promote tumor growth and progression as well as NAD+ metabolism might influence the senescence-associated secretory phenotype (SASP) 
as discussed in the recent paper of Nacarelli et al. [69]. In their research, it was shown that increased NAD+ influences the inflammatory signaling of senescent cells in vivo in mouse models of pancreatic and ovarian cancers through the higher HMGAs and nicotinamide phosphoribosyltransferase (NAMPT) expression, which promotes the proinflammatory SASP through NAD+-mediated suppression of AMPK kinase, leading to suppression of the p53mediated inhibition of p38 MAPK and enhanced NF- $\kappa$ B activity [69]. Moreover, FK866, a compound which inhibits nicotinamide-recycling enzyme NAMPT/PBEF, which is the bottleneck for NAD biosynthesis, resulted in anticancer effect [70] as a tumor apoptosis inducer due to NAD+ depletion [71].

It seems that $\mathrm{NAD}+$ levels are a critical protective factor in early carcinogenesis and might become a detrimental factor later in the cancer progression and promotion phase. Namely, during cancer promotion, progression and treatment-increased NAD+ levels could have deleterious effects on the malignancy process due to increased cell survival, growth advantage, increased resistance to radio and chemotherapy, and promotion of inflammation (reviewed in [65]). The tumor promoting vs. inhibiting properties of $\mathrm{NAD}+$ depend on the stages of cancer development and $\mathrm{NAD}+$ concentration/time-dependent activation of PARPs and sirtuins, which interfere with the cell survival. Sirtuins and PARPs could have both procancer and anticancer effects, and their role in cancer prevention and promotion remains to be fully elucidated [72-77].

1.5. Cancer and Mitochondrial Damage. There are many environmental agents (e.g., radiation, pollutants, and hypoxia) that humans are exposed to through their lives which damage mitochondria and cellular respiration through increased generation of reactive oxygen species (ROS). Therefore, ROS-induced damage to the respiratory system promotes a hypoxic-like state [31], stabilizes the transcription factor HIF, and upregulates glucose transporters into the cell. Additionally, oncogenes have to turn on because they are the transcription factors that upregulate the transporters for glucose and glutamine. The efficiency of mitochondrial oxidative phosphorylation decreases with age, and pseudohypoxia increases which leads to increased apoptosis (every day, 50-70 billion cells of a human body activate apoptotic death). However, in rare cases, a "renegade cell" decides not to sacrifice itself and undergo apoptotic cell death for higher purposes-to preserve the organism. Contrarily, in order to preserve its own life, a "selfish renegade cell" activates a prehistoric program in order to obtain enough energy levels. The aforementioned program activates fermentation and consequently shuts down genomic stability, tumor-suppressive control mechanisms, and mitochondrial apoptotic response [78] allowing such a cell to enter its primitive state. Activation of such processes results in a higher entropy state level inside the cell. A typical cell is a highly ordered low entropy system and invests much energy to keep the entropy of the system low. So as to keep up stable entropy, which is far from thermodynamic balance, living systems use information and energy. Energy loss due to impaired mitochondria limits supply of energy invested for damage repair, and genomic stability increases entropy and impairs order of the cell organization. Namely, glycolysis generates only two moles of ATP per one mol of glucose whereas oxidative phosphorylation generates about $36 \mathrm{mols}$ of ATP per mol of glucose [79] (Figure 1). Hence, carcinogenesis represents a reverse process with the progressive functional decline, disordered morphology, and accumulation of mutations. Energy restriction due to mitochondrial dysfunction might represent the metabolic initiator that "triggers the genetic mutations that drive the somatic evolution of the malignant phenotype" [80].

In cases of glucose deprivation, efficient glucose consumption and catabolism are critical for survival. It was observed that cells switch to glycolysis in combination with lactate dehydrogenase as an adaptation to limited glucose availability [81]. When NAD+ levels within the cell become critically limited, both the TCA cycle in the mitochondria and glycolysis in the cytoplasm can be halted. Despite having an excess of available glucose, this can lead to cell death [82-85]. A less severe reduction in NAD+ levels (e.g., from 30 to $85 \%$ ) has been observed in the muscle tissue of aged mice with an associated deterioration in mitochondrial function but not glycolysis [6, 64, 86-88]. It seems that cytoplasmic NAD+ pool is less susceptible to scarcity since "cytoplasmic $\mathrm{NAD} / \mathrm{NADH}$ ratios range between 60 and 700 in a typical eukaryotic cell, while mitochondrial NAD/NADH ratios are maintained at 7 to 8 " $[89,90]$. The availability of NAD+ is thus critical for mitochondrial function [91-93].

1.6. Is the "Default" Metabolic Program Incorporated in the Cells of Multicellular Organisms' Glycolysis or Oxidative Phosphorylation? It seems that cancer does not develop as a result of hypoxia due to damaged mitochondria or cell mass growth (hypoxic regions of tumors) that leads to impaired aerobic respiration as was first hypothesized by Warburg [31]. Some studies suggest that mitochondria are not damaged in some cancer cells [94-96], as discussed in the previous paragraph, and cancer cells seem to use glycolytic metabolism prior to the exposure to hypoxic conditions [97] as observed in leukemic cells [50,98] and lung tumors which use aerobic glycolysis even though these tumor cells are exposed to high oxygen levels during tumorigenesis $[99,100]$. Alteration in the metabolic switch to the aerobic glycolysis by cancer cells may thus result in the prehistoric (re)program that reverses premalignant cells to an embryonic program that supports cell growth by nutrient acquisition and metabolism. Before oxygen was formed in the atmosphere, proliferation and fermentation was the dominant phenotype and the default state of metazoan cells [101]. According to Szent-Györgyi [101], cancer is a condition of unrestricted cell development, which is typical of free-living cells 500,000 million years ago, before the existence of multicellular life. Cancer is a normal growth from before half a billion years ago, preceding the Cambrian time frame. That was before plants and before oxygen-rich atmosphere; life was just fermentation, with boundless telomerase. When nutrients are available, the unicellular organisms have evolutionary pressure to multiply as soon as possible by 


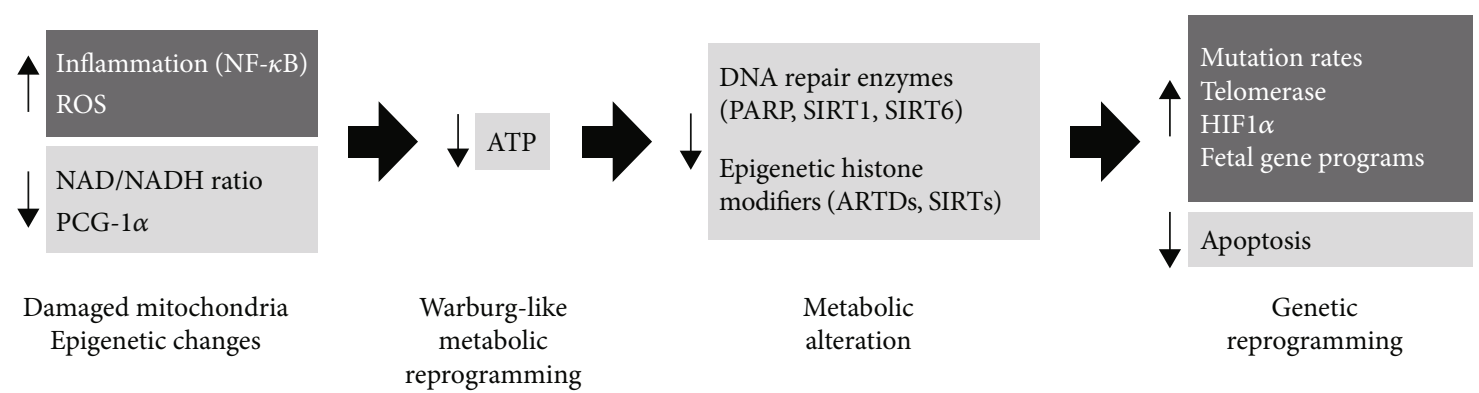

FIGURE 2: Metabolic alterations produce genetic alterations (activation of oncogenes and repression of tumor suppressor genes) which influence cancer development. What the causes are of metabolic alteration is still a matter of debate. Potential candidates involved in the metabolic switch from respiration to fermentation are increased inflammation, increased ROS formation, overstimulation of PARPs, decreased intracellular energy levels, and damaged respiration.

fermentation of glucose to generate biomass, which enables them to maintain the building blocks needed to produce a new cell [97]. In 1940, the French biologist Jacques Monod was the first to discover that genes can be regulated by metabolic readjustment in the experiment with $E$. coli fed on glucose or lactose sugar [102]. Although anaerobic glycolysis is less efficient, it is much more rapid than oxidative phosphorylation. Warburg observed that in the same amount of time a normal cell takes to consume one glucose molecule through OXPHOS, the cancer cell consumes 13 glucose molecules, only one of which through OXPHOS [103]. Such a switch can be explained from the evolutionary viewpoint as this may have helped a unicellular organism to speedily monopolize sugars when available and create an unfavorable environment for competing microorganisms [104].

1.7. Why Do Cancer Cells Prefer a Relatively Inefficient Way (in terms of ATP Production) of Extracting Energy from Glucose? Warburg effect enables cancer cells to convert nutrients into building blocks to form different macromolecules in order to divide fast. Cancer cells must be directed either to cell death or to adaptation to a glycolytic phenotype once their cells reach the oxygen diffusion limit and become hypoxic. If "renegade cells" do not shift to such a primitive form of energy, they will die from apoptosis or lack of ATP. Therefore, cells deficient in ATP often undergo apoptosis [105]. Contrary, by activating glycolysis, "a renegade cell" stimulates cell division and suppresses apoptosis and differentiation [14] as well as the "multiunit teamwork." Such a cell evolved to survive on its own. When cooperation is stopped, and fermentation is preferred, differentiation and specialization are reversed to a more primitive form, and transition to dedifferentiated cells is favored. Such a cell passes the energy needed for self-preservation/regeneration to increased reproduction; consequently, energy for the repair of cells and also the adaptive response to stress as cell cycle arrest regulation and apoptotic removal of damaged cells is depleted. Furthermore, glycolysis significantly diminishes cellular oxidative stress [106]. Both glucose and glutamine-derived glutamate are needed for synthesis of glutathione, which provides high antioxidant capacity and protect cancer cells from elevated ROS formation during chemo- and radiotherapies [107-109].
1.8. Why Did Evolution Preserve the Ability of Cells to Activate Aerobic Glycolysis? The antagonistic pleiotropy hypothesis would explain fermentation as a beneficial process to the organism's fitness at the first week of embryo life when fast-growing cells of an embryo resemble more a cancer mass than normal differentiated tissue. An embryo must survive the first days without blood supply and oxygen. When the ovum reaches the uterus, it develops into a blastocyst consisting of over 100 cells. Upon entering the uterus, the embryo attaches into the uterine lining. Only after the embryo reaches the womb does it obtain blood supply and oxygen, which enables its organized growth [110]. However, later in life, the ability to activate "cancer genes" to drive glycolysis could become detrimental to the organism's fitness as a cell might become cancerous.

What is more, anaerobic glycolysis is activated during short, intense exercise, providing energy to escape during fight-or-flight response. After only 10-30 seconds of shortduration high-intensity anaerobic exercise, the majority of cellular energy come from the anaerobic glycolytic system manifested in the elevation of the blood-lactate level. This system provides ATP for up to 2-3 minutes. Then, the generation of energy switches back to oxidative phosphorylation [111-113]. While the acute switch from oxidative phosphorylation to anaerobic glycolysis is triggered by high-intensity anaerobic training, the cause of the permanent switch to chronic glycolysis remains unknown (Figure 2). One trigger might be increased and permanent inflammation and oxidative stress, which stabilize HIF-1-alpha, which advances a hypoxic-like (Warburg effect) state in the cell resulting in metabolic reinventing toward glycolysis and thus encouraging tumor development [114-116]. Anaerobic glycolysis and imperfect respiratory chain produce a lot of ROS and frame an endless loop which creates significantly more damage to mtDNA and decreases energy formation from oxidative phosphorylation and further invigorates fermentation.

1.9. CSC Metabolic Reprogramming. The cancer stem cell (CSC) hypothesis states that malignant tumors are initiated and maintained by a population of tumor cells that share similar biologic properties to normal adult stem cells [117]. Transformation of a normal stem cell into a CSC may occur 
through dysregulation of the proliferation and differentiation pathways or by inducing oncoprotein activity [118]. An alternative is the potential dedifferentiation of mutated cells so that these cells acquire stem cell-like characteristics [119], which is applicable to cells of all origins. It was observed that non-CSCs could be shifted to CSCs and vice versa in response to intrinsic and/or microenvironmental signals (e.g., oncogenes, tumor suppressor genes, hypoxia, oxidative stress, nutrient starvation, and epigenetics), which means that metabolic reprogramming might play a significant role during CSC transition [37]. Menendez et al. [37] argue that CSC bioenergetics might be another cancer and that metabolic reprogramming of CSCs has cancer-causing action. Increased glycolytic activity observed in early embryonic cells and high proliferation and diffusion are similar (or being reactivated) in cancer stem cells, which resume a more primitive metabolic pattern of energy production [13]. Cancer stem cells express the same metabolic defect as seen in all types of cancer cells. Mitochondrial function, redox status, and ROS formation play an important role in differentiation, maintenance, and self-renewal of $\mathrm{CSC}^{13}$. As in cancer cells, the stimulation of aerobic glycolysis supports, while the blockade of glycolytic enzymes blunts cancer-like metabolic reprogramming, phenomena observed in Induced Pluripotent Stem Cells (iPSCs) [120-123]. Even in the absence of genetic alterations, the Warburg effect and inhibition of OXPHOS are triggered in iPSCs by two primum movens: downregulation of the expression of the catalytic subunit of the AMP-activated protein kinase (AMPK) [124] and H+-ATPase synthase-geared metabolism switch [125-127]. Increased glycolysis in the presence of $\mathrm{O}_{2}$ and impaired oxidative phosphorylation are observed in both embryonic cells and CSC and other tumor cells [128].

1.10. Reprogramming of the Glycolytic Metabolism and Oxidative Phosphorylation: Is the Trigger the Inflammatory Stresses? Numerous studies indicate a strong link between chronic inflammation and cancer (reviewed in [129-138]). Although mechanisms of chronic inflammation are very complex and the precise role of increased inflammation and cancer remain largely unknown, a nuclear factor- $\kappa \mathrm{B}$ (NF$\kappa \mathrm{B})$, considered as the master activator of inflammation [139], and p53, the major tumor suppressor, play a pivotal role. Activation of the NF-kappaB system increases the apoptotic resistance, activates the chronic inflammatory response, and reduces the autophagic cleansing [140]. Besides, macrophages that secrete cytokines and growth factors are attracted by the inflammatory response which promotes tumor cell growth and metastasis [141].

Chronic inflammation and accumulation of oxidative stress during aging also lead to NAD+ depletion [142], resulting in loss of sirtuin and PARP activity. Chronic inflammation will result in increased ROS formation leading to a decrease in intracellular NAD+ and cell death via energy restriction as a result of DNA strand breaks and PARP activation [143]. For example, in the brain cells, increased PARP activity, which leads to decreased $\mathrm{NAD}+$, has been shown to decrease ATP as well as cause cell death $[144,145]$. In particular, DNA repair enzyme PARPs utilize a lot of intracellular
$\mathrm{NAD}+(100$ molecules of NAD+ when activated by one DNA break) and are in this manner in rivalry with sirtuins for the constrained supply of NAD+. Deacetylation by SIRT1 reprograms inflammation and cancer [146]. Constrained accessibility of NAD+ and reduced expression of SIRT1 may sustain aberrant chromatin structure and functions. Subsequently, reduced cellular NAD+ limits the efficacy of sirtuins (SIRT1), possibly deacetylating tumor suppressor proteins such as p53 [147]. p53 differentially controls a cluster of its target genes, encompassing the arrest of cell cycle, autophagy, apoptosis, and senescence, to apply its function in the damage of DNA and suppression of tumors. Consequently, a depletion of p53 gives a growth advantage to tumor cells; for example, it empowers cell survival under constraining nutrient conditions [148]. Moreover, NAD+-dependent tankyrases (PARP-5a and PARP-5b), which control telomerase activity and telomere maintenance, may likewise impact the cancer-causing process [149].

SIRT1 likewise impacts inflammation and cancer by straightly deacetylating targets like p65, p53, and NF- $\kappa \mathrm{B}$, which produce proinflammatory products. NAD+ levels steadily decline with age [129] due to loss of SIRT3 activity in mitochondria, loss of PARP activity, and increased levels of NADase CD38 during aging $[86,142]$. Since NF- $\kappa$ B regulates the CD38 expression [150], the increase in low-grade inflammation with age might be the reason for NAD+ decline. Consequently, cells with high levels of CD38 use less oxygen, have increased lactate, and have dysfunctional mitochondria [142]. During chronic inflammation, NAD+ levels and SIRT transcription and/or protein levels are persistently reduced in different tissues [151]. Chronic inflammation and the release of proinflammatory mediators might thus reprogram cellular metabolism and energy production. For example, the induction of anabolic glycolysis is observed in cells of the immune system (e.g., monocytes and macrophages) exposed to inflammatory stress [152-155]. With increased age, the innate immune system does not efficiently clears the senescent cells as emitters of signals that drive inflammation and the vicious cycle initiates [156].

\subsection{Prevention of Glycolysis and Reactivation of Mitochondrial Oxidative Metabolism: Approaches That Target Cell Energy Metabolism and Restore Mitochondrial Function}

1.11.1. Targeting Aerobic Glycolysis Pathways and the Warburg Effect. Many compounds affect aerobic glycolysis and would be efficient in depleting ATP in cells with mitochondrial defects and triggering cell death. Different small molecules target aerobic glycolysis and could be used as novel tumor therapeutics, for example, 2-deoxyglucose [157], lonidamine, 3-bromopyruvate [158, 159], imatinib, oxythiamine, and 6-aminonicotinamide [160-162]. Another way of action is to inhibit glucose transport by phloretin [163] or stimulation of mitochondrial oxidative metabolism through overexpression of mitochondrial frataxin, which inhibits tumor growth $[164,165]$. Already in clinical use are imatinib and trastuzumab (Herceptin), which target signaling pathways linked to glucose metabolism $[98,166]$, primarily in those 
individuals with mutations in specific receptors linked to the insulin-like growth factor 1-Akt/protein kinase B (IGF-1/PI3K/Akt) pathway. Many studies are showing that the Warburg effect can be targeted with dichloroacetate (DCA) and increased mitochondrial activity of glutaminolysis with arsenic trioxide (ATO). It was observed that DCA induces apoptosis in cancer cells but does not induce apoptosis in normal cells [167-172].

There are many agents that can act as anti-Warburg agents. Their way of acting is to increase the NAD+ levels and promote the oxidative metabolism [173]. For example, SIRT3 can restrain the "Warburg effect" by controlling HIF- $1 \alpha$ and change the cancer cell metabolism programming from highly glycolytic toward oxidative phosphorylation $[116,174,175]$. Besides, by inactivating HIF-1 $\alpha$, SIRT1 represses HIF-1 target genes and adversely effects tumor growth and angiogenesis [176]. By increasing levels of sirtuins, PARPs, and PGC- $1 \alpha$, oxidative metabolism, inflammation, epigenetic gene silencing, cell cycle control, genome stability, apoptosis, stress resistance, energy efficiency, DNA repair, cell death, genome integrity, cellular differentiation, gene expression, and antiaging could be promoted.

Finally, mitochondria could be used as a potential anticancer drug target. The apoptotic process could be regulated by reactivating or by transferring mitochondria [5].

\subsubsection{Enhancing Mitochondrial Biogenesis and Efficacy and} Boosting Oxidative Metabolism. By enhancing the bioavailability of NAD+, oxidative capacity of mitochondria could be restored. NAD+ levels could be raised with exercise, restriction of calories (CR), and ingestion of NAD+ precursors and intermediates. Alternatively, NAD + bioavailability can be increased by using poly-ADP-ribose polymerase (PARP), CD 38, and SAM1 inhibitors [60, 65, 177-185]. Consequently, increased NAD+ levels could activate PARPs and sirtuins which control the genes that play a role in the process of DNA repair and maintenance [173]. Additionally, different $\mathrm{NAD}(+)$ precursors can be used through distinct metabolic pathways to form $\mathrm{NAD}(+)$, such as nicotinamide, nicotinamide mononucleotide, tryptophan, nicotinic acid, and nicotinamide riboside. Further, consumption of foods that contain molecules necessary for respiratory enzyme function (riboflavin, nicotinamide, iron salts, and pantothenic acid) could help to maintain health when it is combined with dietary energy restriction [186] since CR increases the efficiency of the electron transport in the mitochondrial respiratory chain [187]. Pyrroloquinoline quinone (PQQ) might increase the number and efficiency of mitochondria. PQQ interacts with cell signaling pathways and influences energy-related mitochondrial metabolism [188]. The mitochondrial biogenesis is stimulated through a pathway that activates the CAMP response element-binding protein (CREB) and peroxisome proliferator-activated receptor gamma coactivator-1alpha (PGC-1alpha) [189].

While raising $\mathrm{NAD}+$ levels for cancer prevention might be beneficial, increasing NAD+ levels might be detrimental during the precancerous stage or once the cancer is formed [65] (discussed in the previous paragraph).
1.11.3. Increasing the Intracellular Oxygen Level with Hyperbaric Oxygen Therapy. Hyperbaric oxygen therapy raises oxygen levels in tumors and reverses the cancerpromoting effects of tumor hypoxia [190, 191]. By enhancing oxygen delivery to cells, more ATP can be obtained through oxidative phosphorylation since cells make use of oxygen acting as a final electron acceptor in the process of generating ATP in their mitochondria and mitochondrial integrity could be preserved [192]. Poff et al. [193] observed that a combination of the ketogenic diet with hyperbaric oxygen therapy resulted in a noticeable drop in blood sugar and the rate of tumor development and increased mean survival of mice with systemic metastatic cancer.

1.11.4. Increasing Regulation of Contact Inhibition (DensityDependent Inhibition) and Proliferation. Due to the loss of growth control, the growth and division of cells are uncontrolled. Cells should be informed that they are a part of a multicellular organism and that they have to obey the control of proliferation or to activate apoptosis if being damaged. This could be achieved by increasing the response to the signals that cause healthy cells to cease proliferation and enter the G0 phase and by decreasing the production of growth factors that stimulate cancer cells to own proliferation [194-196].

1.11.5. Targeting Glucose and Elevating Blood Ketone Bodies through a Calorie-Restricted Ketogenic Diet (KD-R). The energy metabolism in glycolysis-dependent tumors can be targeted by a transition from carbohydrate to ketones. Healthy cells can be protected from such glycolytic inhibition, and the brain can be protected from hypoglycaemia by elevating blood ketones, which occurs when a lowcarbohydrate and a high-fat ketogenic diet is carried out in limited amounts [34]. Exogenous ketone supplementation on its own inhibits cancer cell proliferation and viability in vitro, slows tumor growth, and prolongs survival in vivo [197]. Caloric restriction/KD-R reduces carbons needed in glycolytic and pentose phosphate pathways in order to provide ATP, precursors for lipid and nucleotide synthesis and formation of antioxidant glutathione. Due to impaired mitochondrial function, cancer cells are depending on substrate-level phosphorylation, and during ketone body metabolism, mSLP is bypassed. Ketone bodies may elicit their anticancer effects, most likely by glycolytic enzyme inhibition [198]. Numerous research studies documented that in vitro cancer cells were deficient in metabolizing of ketone bodies [199, 200]. Ketone bodies generate ATP energy only through oxidative respiration in the mitochondria and cannot be fermented. While dietary energy reduction lowers blood glucose levels and restricts the energy supply to cancer cells, some of the tumor cells might still obtain enough energy to survive due to the endogenous glucose and amino acid influx.

1.11.6. Targeting Glutamine. For cell growth and division, cells need a supply of carbon, nitrogen, free energy, and reducing equivalents, which can be obtained through glucose and glutamine metabolism [97]. Glutamine functions as a 
significant energy metabolite for some cancers. For example, tumors with deregulated MYC expression may be less sensitive to inhibition of glycolysis than tumors with overactivation of the Akt pathway [178, 201]. Glutamine provides a source of carbon and nitrogen needed for nucleotide synthesis, and targeting glutamine metabolism with the glutamine antagonist 6-diazo-5-oxo-norleucine (DON) might be used in cancer treatment [202-204]. For example, it was shown in two glioblastoma mouse models that administration of DON and calorically restricted ketogenic (KD-R) diet killed tumor cells, reversing disease symptoms and increasing overall mouse survival. Simultaneous administration of DON and KD-R both targeted substrate-level phosphorylation reactions in mitochondria (glutaminolysis) and in the cytoplasm (glycolysis), respectively, thus enabling ATP formation and synthesis of proteins, nucleotides, and lipids [205]. It should be stressed that glutamine is needed for appropriate functioning of the immune system and the gut [206]; thus, glutamine targeting is more demanding than glucose targeting.

1.11.7. "Press-Pulse" Therapeutic Strategy. The team of Seyfried developed a so-called "press-pulse" therapeutic strategy $[107,207]$. The general concept of press disturbances (chronic metabolic stress on tumor cell energy disturbance) and pulse disturbances (acute metabolic stressors that restrict glucose and glutamine availability) could be applied for the management of cancer. Press therapies reduce systemic glucose concentrations and elevate ketone bodies; pulse therapies use cocktails which interfere with glycolysis and glutaminolysis metabolic pathways [107, 207].

\subsubsection{Targeting Insulin/Insulin-Like Growth Factor (IGF)} Signaling, Mammalian Target of Rapamycin (mTOR), and AMP-Activated Protein Kinase (AMPK) Pathways. Metabolic therapies that lower circulating glucose levels were reported to significantly reduce growth and progression of numerous tumor types [14]. A number of epidemiological studies initially concluded that in patients with diabetes who controlled their blood sugar levels by taking metformin, the development of cancer was less likely. It was also observed that their survival rate was improved once cancer was initiated. Several retrospective studies indicated that people with diabetes had increased cancer mortality compared with nondiabetics and that people with diabetes on metformin had a substantially ( $40 \%)$ reduced cancer burden compared with diabetics on other treatments [208]. For example, glucose reduction lowers insulin and IGF-1 levels, which is required for driving tumor cell metabolism and growth $[209,210]$. Caloric restriction specifically influences the IGF-1/PI3K/Akt/HIF-1 $\alpha$ signaling pathway, which regulates several cancer hallmarks like evasion of apoptosis, cell proliferation, and angiogenesis [14]. Diabetes drugs metformin and phenformin might have benefit in cancer prevention as activators of AMPK in cells. AMPK is activated by also salicylate in vitro and by "nutraceuticals" such as resveratrol, epigallocatechin gallate, and berberine, which activate AMPK by inhibiting mitochondrial ATP production [211]. AMPK is also activated in the resting muscle with 5-aminoimidazole-4-carboxamide-riboside
(AICAR), which enters the muscle and is phosphorylated to ZMP (5-aminoimidazole-4-carboxamide-1- $\beta$-D-ribofuranosyl- $5^{\prime}$-monophosphate, an AMP analog). ZMP is a nucleotide that mimics the effect of $5^{\prime}$-AMP [212-214]. 3,3' -Diindolylmethane (DIM) from cruciferous vegetables and epigallocatechin gallate (EGCG) from green tea have been reported to be effective AMPK activators in a prostate or breast cancer model system, both in vitro and in vivo [215]. Additionally, AMPK was demonstrated to suppress tumor growth in vivo as a negative regulator of the Warburg effect [216]. AMPK in muscles is activated, in response to both in vivo exercise and ex vivo contraction $[217,218]$. The varied role of AMPK on cancer cell survival and tumor progression and suppression is explained in detail elsewhere [219]. The induction of AMPK activity inhibits the activity of rapamycin (mTOR) [220]. Mammalian target of rapamycin (mTOR) regulates a translational control over cell division, growth, and energy metabolism, while IGF-1/Akt regulates the transcriptional regulators of these processes. The inhibition of apoptosis and the promotion of growth and division are, therefore, the result of the activated IGF/Akt pathway [221]. A serine/threonine protein kinase mTOR controls the growth, proliferation, motility, and survival of cells; protein synthesis; and transcription $[222,223]$ in response to nutrients (e.g., glucose and amino acids), growth factors (e.g., increased levels of insulin, IGF-1, and platelet-derived growth factor (PDGF)), and cellular energy status (ATP). $\mathrm{CR}$ and p53 (a nuclear transcription factor with a proapoptotic function) may also inhibit mTOR activity [148].

1.11.9. Shifting from Anabolic to Catabolic Metabolism Suppresses High Rates of Proliferation. Anabolic pathways that advance growth are stimulated in cancer by means of tumorigenic mutations, especially PI3K-mTOR signaling [224]. PI3K-Akt-mTOR network signaling, where many oncogenes and tumor suppressors reside, is acquired with minimal reliance on external stimulation by growth factors [225]. Additionally, glucose metabolism generates glycolytic intermediates (hexosamine pathway, PPP, and one-carbon metabolism) which promote anabolic pathways that support cell growth [226]. On the other hand, only a couple of short periods of fasting activates AMPK, which triggers repair and catabolic processes. Alongside, AMPK-mediated inhibition of mTOR activity [226] and downstream anabolic pathways establishes separation of anabolic and catabolic processes [227]. Tumor cells have aberrant activation of mTORC1 that evokes an anabolism leading to nucleotide, protein, and lipid synthesis. A depletion of tumor suppressors, such as p53, or activation of oncogenes, e.g., MYC, to a greater extent enhances an anabolic growth program by metabolic gene transcriptional regulation.

Currently, there are many other strategies under investigation targeting mitochondrial energy metabolism to 2inhibit or delay tumor growth. Some of them deal with DNA methylation pattern, epigenetic reprogramming, and aberrant microRNA (miRNA) levels and/or investigate the role of intermediates of the Krebs cycle on "nonmetabolic" signaling which alters the immune system, the role of DJ-1 (Parkinsonism-associated deglycase) as a modulator 
of mitochondrial metabolic efficiency and a switch between glycolysis and oxidative phosphorylation, and the role of bouchardatine in suppressing cancer by disrupting its metabolic pathways via activating the SIRT1PGC-1 $\alpha$-UCP2 axis. Detailed descriptions of their principles are beyond the scope of this paper. More information can be found elsewhere [228-231].

1.12. Chemoresistance. Drug-resistant tumor cells arise in a large part from the damage to respiration in bystander precancerous cells. While cytotoxic drugs and radiation create tumor cells that become highly resistant to the classical treatment approaches, this is not probable when dietary energy reduction and approaches aimed at reversing abnormal energy metabolism and growth behavior in tumor cells are used [107, 232]. Chemoresistance is the result of the fermentation metabolism in the tumor cells. Glucose and glutamine contribute to the synthesis of glutathione, which protects tumor cells from oxidative stress [205]. Inhibition of glycolysis in cancer cells increases the sensitivity to common anticancer agents and overcomes the drug resistance [232]. Dietary restriction, periodic fasting, and fastingmimicking diets are emerging as interventions used to prevent and treat cancer in combination with chemo- and radiotherapy [233-235].

\section{Conclusion}

A clear understanding of the origins of cancer is the basis of successful strategies for effective cancer prevention and management. Results are indicating that the carcinogenic process is not driven by the accumulation of random or stochastic genetic mutations, but instead, a mitochondrial metabolic disease [4] was presented. However, it remains to be elucidated what exactly triggers the reprogrammed metabolism in cancer cells. Additional studies are needed to investigate the causation-consequence relationship between metabolic abnormalities and the causation of the genetic mutations and, on the other hand, the mutation ability to trigger the metabolic abnormalities.

Both metabolic and standard cytotoxicity-based treatment approaches should be coupled. Strategies that restore mitochondrial metabolism/functions could have both tumor preventive (e.g., caloric restriction or intermittent fasting) and therapeutic implications in cancer (use of drugs, such as glutamine antagonist and 6-diazo-5-oxo-L-norleucine (DON), and others including KD-R). Evidence was presented that restoring redox homeostasis and reactivation of mitochondrial oxidative metabolism are important factors in cancer prevention. Preclinical studies are needed, followed by controlled-randomized clinical trials, investigating strategies to restore mitochondrial metabolism as well as synergistic effect of metabolic and standard cytotoxicity-based treatment approaches. Without findings of additional studies, no specific therapy can be currently favorited. The efficacy of the proposed treatment approaches should be further studied to determine their potential for clinical use in the future.

\section{Conflicts of Interest}

The authors declare that they have no conflicts of interest.

\section{Acknowledgments}

The authors acknowledge the financial support from the Slovenian Research Agency (research core funding No. P3-0388).

\section{References}

[1] S. G. Baker, "A cancer theory kerfuffle can lead to new lines of research," Journal of the National Cancer Institute, vol. 107, no. 2, p. dju405, 2014.

[2] I. Martincorena, A. Roshan, M. Gerstung et al., "High burden and pervasive positive selection of somatic mutations in normal human skin," Science, vol. 348, no. 6237, pp. 880-886, 2015.

[3] I. Martincorena, J. C. Fowler, A. Wabik et al., "Somatic mutant clones colonize the human esophagus with age," Science, vol. 362, no. 6417, pp. 911-917, 2018.

[4] T. N. Seyfried, "Cancer as a mitochondrial metabolic disease," Frontiers in Cell and Development Biology, vol. 3, 2015.

[5] B. A. Kaipparettu, Y. Ma, J. H. Park et al., "Crosstalk from non-cancerous mitochondria can inhibit tumor properties of metastatic cells by suppressing oncogenic pathways," PLoS One, vol. 8, no. 5, p. e61747, 2013.

[6] R. L. Elliott, X. P. Jiang, and J. F. Head, "Mitochondria organelle transplantation: introduction of normal epithelial mitochondria into human cancer cells inhibits proliferation and increases drug sensitivity," Breast Cancer Research and Treatment, vol. 136, no. 2, pp. 347-354, 2012.

[7] K. Hochedlinger, R. Blelloch, C. Brennan et al., "Reprogramming of a melanoma genome by nuclear transplantation," Genes \& Development, vol. 18, no. 15, pp. 1875-1885, 2004.

[8] L. Li, M. C. Connelly, C. Wetmore, T. Curran, and J. I. Morgan, "Mouse embryos cloned from brain tumors," Cancer Research, vol. 63, no. 11, pp. 2733-2736, 2003.

[9] R. G. McKinnell, B. A. Deggins, and D. D. Labat, "Transplantation of pluripotential nuclei from triploid frog tumors," Science, vol. 165, no. 3891, pp. 394-396, 1969.

[10] M. Koura, H. Isaka, M. C. Yoshida, M. Tosu, and T. Sekiguchi, "Suppression of tumorigenicity in interspecific reconstituted cells and cybrids," Gan, vol. 73, pp. 574-580, 1982.

[11] B. A. Israel and W. I. Schaeffer, "Cytoplasmic suppression of malignancy," In Vitro Cellular \& Developmental Biology, vol. 23, no. 9, pp. 627-632, 1987.

[12] A. N. Howell and R. Sager, "Tumorigenicity and its suppression in cybrids of mouse and Chinese hamster cell lines," Proceedings of the National Academy of Sciences, vol. 75, no. 5, pp. 2358-2362, 1978.

[13] R. Scatena, "Mitochondria and cancer: a growing role in apoptosis, cancer cell metabolism and dedifferentiation," Advances in Experimental Medicine and Biology, vol. 942, pp. 287-308, 2012.

[14] T. N. Seyfried and L. M. Shelton, "Cancer as a metabolic disease," Nutrition \& Metabolism (London), vol. 7, no. 1, p. 7, 2010 . 
[15] J. Kim and C. V. Dang, "Cancer's molecular sweet tooth and the Warburg effect: figure 1," Cancer Research, vol. 66, no. 18, pp. 8927-8930, 2006.

[16] X. Liu, C. N. Kim, J. Yang, R. Jemmerson, and X. Wang, "Induction of apoptotic program in cell-free extracts: requirement for dATP and cytochrome c," Cell, vol. 86, no. 1, pp. 147-157, 1996.

[17] S. P. Mathupala, Y. H. Ko, and P. L. Pedersen, “The pivotal roles of mitochondria in cancer: Warburg and beyond and encouraging prospects for effective therapies," Biochimica et Biophysica Acta (BBA) - Bioenergetics, vol. 1797, no. 6-7, pp. 1225-1230, 2010.

[18] V. C. Fogg, N. J. Lanning, and J. P. MacKeigan, "Mitochondria in cancer: at the crossroads of life and death," Chinese Journal of Cancer, vol. 30, no. 8, pp. 526-539, 2011.

[19] J. Du, "Hypothesis of mitochondrial oncogenesis as the trigger of normal cells to cancer cells," Medical Hypotheses, vol. 82, no. 6, pp. 744-747, 2014.

[20] A. L. Sessions, D. M. Doughty, P. V. Welander, R. E. Summons, and D. K. Newman, "The continuing puzzle of the great oxidation event," Current Biology, vol. 19, no. 14, pp. R567-R574, 2009.

[21] J. Raymond and D. Segrè, "The effect of oxygen on biochemical networks and the evolution of complex life," Science, vol. 311, no. 5768, pp. 1764-1767, 2006.

[22] A. Adjiri, "DNA mutations may not be the cause of cancer," Oncology and Therapy, vol. 5, no. 1, pp. 85-101, 2017.

[23] P. Hardy and H. Zacharias, "Reappraisal of the HansemannBoveri hypothesis on the origin of tumors," Cell Biology International, vol. 29, no. 12, pp. 983-992, 2005.

[24] K. L. Manchester, "Theodor Boveri and the origin of malignant tumours," Trends in Cell Biology, vol. 5, no. 10, pp. 384-387, 1995.

[25] B. Vogelstein, N. Papadopoulos, V. E. Velculescu, S. Zhou, L. A. Diaz, and K. W. Kinzler, "Cancer genome landscapes," Science, vol. 339, no. 6127, pp. 1546-1558, 2013.

[26] L. B. Alexandrov, Australian Pancreatic Cancer Genome Initiative, S. Nik-Zainal et al., "Signatures of mutational processes in human cancer," Nature, vol. 500, no. 7463, pp. 415421, 2013.

[27] T. N. Seyfried, R. E. Flores, A. M. Poff, and D. P. D'Agostino, "Cancer as a metabolic disease: implications for novel therapeutics," Carcinogenesis, vol. 35, no. 3, pp. 515-527, 2014.

[28] T.-L. Wang, C. Rago, N. Silliman et al., "Prevalence of somatic alterations in the colorectal cancer cell genome," Proceedings of the National Academy of Sciences, vol. 99, no. 5, pp. 30763080, 2002.

[29] D. E. Brash, T. P. Heffernan, P. Nghiem, and R. J. Cho, "Carcinogenesis: UV radiation," in Textbook of Aging Skin, pp. 887-902, Springer, Berlin Heidelberg, 2017.

[30] T. N. Seyfried, "Genes, respiration, viruses, and cancer," in Cancer as a Metabolic Disease, pp. 145-176, John Wiley \& Sons, Inc., 2012.

[31] O. Warburg, "On the origin of cancer cells," Science, vol. 123, no. 3191, pp. 309-314, 1956.

[32] S. Weinhouse, O. Warburg, D. Burk, and A. L. Schade, "On respiratory impairment in cancer cells," Science, vol. 124, no. 3215 , pp. 267-272, 1956.

[33] J. A. Petros, A. K. Baumann, E. Ruiz-Pesini et al., "mtDNA mutations increase tumorigenicity in prostate cancer,"
Proceedings of the National Academy of Sciences, vol. 102, no. 3, pp. 719-724, 2005.

[34] T. N. Seyfried, "Mitochondria: the ultimate tumor suppressor," in Cancer as a Metabolic Disease, pp. 195-205, John Wiley \& Sons, Inc., 2012.

[35] Á. D. Ortega, M. Sánchez-Aragó, D. Giner-Sánchez, L. Sánchez-Cenizo, I. Willers, and J. M. Cuezva, "Glucose avidity of carcinomas," Cancer Letters, vol. 276, no. 2, pp. 125-135, 2009.

[36] B. Altenberg and K. O. Greulich, "Genes of glycolysis are ubiquitously overexpressed in 24 cancer classes," Genomics, vol. 84, no. 6, pp. 1014-1020, 2004.

[37] J. Menendez, J. Joven, S. Cufí et al., "The Warburg effect version 2.0: metabolic reprogramming of cancer stem cells," Cell Cycle, vol. 12, no. 8, pp. 1166-1179, 2013.

[38] T. N. Seyfried and P. Mukherjee, "Targeting energy metabolism in brain cancer: review and hypothesis," Nutrition \& Metabolism (London), vol. 2, no. 1, p. 30, 2005.

[39] Y. Chen, R. Cairns, I. Papandreou, A. Koong, and N. C. Denko, "Oxygen consumption can regulate the growth of tumors, a new perspective on the Warburg effect," PLoS One, vol. 4, no. 9, 2009.

[40] A. Ramanathan, C. Wang, and S. L. Schreiber, "Perturbational profiling of a cell-line model of tumorigenesis by using metabolic measurements," Proceedings of the National Academy of Sciences, vol. 102, no. 17, pp. 5992-5997, 2005.

[41] A. P. John, "Dysfunctional mitochondria, not oxygen insufficiency, cause cancer cells to produce inordinate amounts of lactic acid: the impact of this on the treatment of cancer," Medical Hypotheses, vol. 57, no. 4, pp. 429-431, 2001.

[42] L. Galluzzi, E. Morselli, O. Kepp et al., "Mitochondrial gateways to cancer," Molecular Aspects of Medicine, vol. 31, no. 1, pp. 1-20, 2010.

[43] C. S. Foster, P. E. Spoerri, P. Glees, and O. Spoerri, "The mode of mitochondrial degeneration in gliomas," Acta Neurochirurgica, vol. 43, no. 3-4, pp. 229-237, 1978.

[44] A. K. Rasmussen, A. Chatterjee, L. J. Rasmussen, and K. K. Singh, "Mitochondria-mediated nuclear mutator phenotype in Saccharomyces cerevisiae," Nucleic Acids Research, vol. 31, no. 14, pp. 3909-3917, 2003.

[45] J. M. Cuezva, M. Krajewska, M. L. de Heredia et al., "The bioenergetic signature of cancer: a marker of tumor progression," Cancer Research, vol. 62, no. 22, pp. 6674-6681, 2002.

[46] M. A. Kiebish, X. Han, H. Cheng, J. H. Chuang, and T. N. Seyfried, "Cardiolipin and electron transport chain abnormalities in mouse brain tumor mitochondria: lipidomic evidence supporting the Warburg theory of cancer," Journal of Lipid Research, vol. 49, no. 12, pp. 2545-2556, 2008.

[47] G. J. Arismendi-Morillo and A. V. Castellano-Ramirez, "Ultrastructural mitochondrial pathology in human astrocytic tumors: potentials implications pro-therapeutics strategies," Journal of Electron Microscopy, vol. 57, no. 1, pp. 3339, 2007.

[48] I. Marin-Valencia, C. Yang, T. Mashimo et al., "Analysis of tumor metabolism reveals mitochondrial glucose oxidation in genetically diverse human glioblastomas in the mouse brain in vivo," Cell Metabolism, vol. 15, no. 6, pp. 827-837, 2012.

[49] P. S. Ward and C. B. Thompson, "Metabolic reprogramming: a cancer hallmark even Warburg did not anticipate," Cancer Cell, vol. 21, no. 3, pp. 297-308, 2012. 
[50] R. L. Elstrom, D. E. Bauer, M. Buzzai et al., "Akt stimulates aerobic glycolysis in cancer cells," Cancer Research, vol. 64, no. 11, pp. 3892-3899, 2004.

[51] P. V. Maximchik, A. V. Kulikov, B. D. Zhivotovsky, and V. G. Gogvadze, "Cellular energetics as a target for tumor cell elimination," Biochemistry (Moscow), vol. 81, no. 2, pp. 65-79, 2016.

[52] D. R. Wise, R. J. DeBerardinis, A. Mancuso et al., "Myc regulates a transcriptional program that stimulates mitochondrial glutaminolysis and leads to glutamine addiction," Proceedings of the National Academy of Sciences, vol. 105, no. 48, pp. 18782-18787, 2008.

[53] M. Janiszewska, M. L. Suva, N. Riggi et al., "Imp2 controls oxidative phosphorylation and is crucial for preserving glioblastoma cancer stem cells," Genes \& Development, vol. 26, no. 17, pp. 1926-1944, 2012.

[54] A. Hall, K. D. Meyle, M. K. Lange et al., "Dysfunctional oxidative phosphorylation makes malignant melanoma cells addicted to glycolysis driven by the V600EBRAF oncogene," Oncotarget, vol. 4, no. 4, 2013.

[55] R. Rossignol, R. Gilkerson, R. Aggeler, K. Yamagata, S. J. Remington, and R. A. Capaldi, "Energy substrate modulates mitochondrial structure and oxidative capacity in cancer cells," Cancer Research, vol. 64, no. 3, pp. 985-993, 2004.

[56] A. Chevrollier, D. Loiseau, P. Reynier, and G. Stepien, "Adenine nucleotide translocase 2 is a key mitochondrial protein in cancer metabolism," Biochimica et Biophysica Acta (BBA) - Bioenergetics, vol. 1807, no. 6, pp. 562-567, 2011.

[57] T. N. Seyfried, L. Shelton, G. Arismendi-Morillo et al., "Provocative question: should ketogenic metabolic therapy become the standard of care for glioblastoma?," Neurochemical Research, 2019.

[58] C. Chinopoulos and T. N. Seyfried, "Mitochondrial substratelevel phosphorylation as energy source for glioblastoma: review and hypothesis," ASN Neuro, vol. 10, p. 175909141881826, 2018.

[59] H. Massudi, R. Grant, G. J. Guillemin, and N. Braidy, "NAD + metabolism and oxidative stress: the golden nucleotide on a crown of thorns," Redox Report, vol. 17, no. 1, pp. 28-46, 2012.

[60] N. Braidy, G. J. Guillemin, H. Mansour, T. Chan-Ling, A. Poljak, and R. Grant, "Age related changes in NAD+ metabolism oxidative stress and Sirtl activity in Wistar rats," PLoS One, vol. 6, no. 4, p. e19194, 2011.

[61] K. M. Ramsey, K. F. Mills, A. Satoh, and S. Imai, "Age-associated loss of Sirt1-mediated enhancement of glucosestimulated insulin secretion in beta cell-specific Sirt1overexpressing (BESTO) mice," Aging Cell, vol. 7, no. 1, pp. 78-88, 2008.

[62] Z. Xu and J. A. Taylor, "Genome-wide age-related DNA methylation changes in blood and other tissues relate to histone modification, expression and cancer," Carcinogenesis, vol. 35, no. 2, pp. 356-364, 2014.

[63] S. Ukraintseva and A. I. Yashin, "Individual aging and cancer risk: how are they related?," Demographic Research, vol. 9, pp. 163-196, 2003.

[64] A. P. Gomes, N. L. Price, A. J. Y. Ling et al., "Declining $\mathrm{NAD}+$ induces a pseudohypoxic state disrupting nuclearmitochondrial communication during aging," Cell, vol. 155, no. 7, pp. 1624-1638, 2013.
[65] B. Poljsak, "NAD+ in cancer prevention and treatment: pros and cons," Journal of Clinical \& Experimental Oncology, vol. 5, no. 4, 2016.

[66] C. Cantó, K. J. Menzies, and J. Auwerx, "NAD+ metabolism and the control of energy homeostasis: a balancing act between mitochondria and the nucleus," Cell Metabolism, vol. 22, no. 1, pp. 31-53, 2015.

[67] P. L. Pedersen, "Tumor mitochondria and the bioenergetics of cancer cells," Progress in Experimental Tumor Research, vol. 22, pp. 190-274, 1978.

[68] C. A. Benavente and E. L. Jacobson, "Niacin restriction upregulates NADPH oxidase and reactive oxygen species (ROS) in human keratinocytes," Free Radical Biology \& Medicine, vol. 44, no. 4, pp. 527-537, 2008.

[69] T. Nacarelli, L. Lau, T. Fukumoto et al., "NAD+ metabolism governs the proinflammatory senescence-associated secretome," Nature Cell Biology, vol. 21, no. 3, pp. 397407, 2019.

[70] A. Pogrebniak et al.et al., "Chemopotentiating effects of a novel NAD biosynthesis inhibitor, FK866, in combination with antineoplastic agents," European Journal of Medical Research, vol. 11, pp. 313-321, 2006.

[71] M. Hasmann and I. Schemainda, "FK866, a highly specific noncompetitive inhibitor of nicotinamide phosphoribosyltransferase, represents a novel mechanism for induction of tumor cell apoptosis," Cancer Research, vol. 63, 2003.

[72] C. M. Whitacre, H. Hashimoto, M. L. Tsai, S. Chatterjee, S. J. Berger, and N. A. Berger, "Involvement of NAD-poly(ADPribose) metabolism in p53 regulation and its consequences," Cancer Research, vol. 55, no. 17, pp. 3697-3701, 1995.

[73] C.-X. Deng, "SIRT1, Is It a Tumor Promoter or Tumor Suppressor?," International Journal of Biological Sciences, vol. 5, pp. 147-152, 2009.

[74] J. Wesierska-Gadek, Z. Q. Wang, and G. Schmid, "Reduced stability of regularly spliced but not alternatively spliced p53 protein in PARP-deficient mouse fibroblasts," Cancer Research, vol. 59, pp. 28-34, 1999.

[75] M. L. Agarwal, A. Agarwal, W. R. Taylor, Z. Q. Wang, E. F. Wagner, and G. R. Stark, "Defective induction but normal activation and function of $\mathrm{p} 53$ in mouse cells lacking polyADP-ribose polymerase," Oncogene, vol. 15, no. 9, pp. 1035-1041, 1997.

[76] X. Wang, K. Ohnishi, A. Takahashi, and T. Ohnishi, "Poly(ADP-ribosyl)ation is required for p53-dependent signal transduction induced by radiation," Oncogene, vol. 17, no. 22, pp. 2819-2825, 1998.

[77] G. Schmid, Z.-Q. Wang, and J. Wesierska-Gadek, "Compensatory expression of p73 in PARP-deficient mouse fibroblasts as response to a reduced level of regularly spliced wild-type p53 protein," Biochemical and Biophysical Research Communications, vol. 255, no. 2, pp. 399-405, 1999.

[78] S. Bartesaghi, V. Graziano, S. Galavotti et al., "Inhibition of oxidative metabolism leads to p53 genetic inactivation and transformation in neural stem cells," Proceedings of the National Academy of Sciences, vol. 112, no. 4, pp. 10591064, 2015.

[79] B. Martinez-Pastor and R. Mostoslavsky, "Sirtuins, metabolism, and cancer," Frontiers in Pharmacology, vol. 3, 2012.

[80] B. R. Frieden and R. A. Gatenby, "Information dynamics in living systems: prokaryotes, eukaryotes, and cancer," PLoS One, vol. 6, no. 7, p. e22085, 2011. 
[81] T. Pfeiffer, S. Schuster, and S. Bonhoeffer, "Cooperation and competition in the evolution of ATP-producing pathways," Science, vol. 292, no. 5516, pp. 504-507, 2001.

[82] C. C. Alano, P. Garnier, W. Ying, Y. Higashi, T. M. Kauppinen, and R. A. Swanson, "NAD+ depletion is necessary and sufficient for poly(ADP-ribose) polymerase-1-mediated neuronal death," The Journal of Neuroscience, vol. 30, no. 8, pp. 2967-2978, 2010.

[83] C. Benavente, M. Jacobson, and E. Jacobson, "NAD in skin: therapeutic approaches for niacin," Current Pharmaceutical Design, vol. 15, no. 1, pp. 29-38, 2009.

[84] W. Ying, C. C. Alano, P. Garnier, and R. A. Swanson, "NAD+ as a metabolic link between DNA damage and cell death," Journal of Neuroscience Research, vol. 79, no. 1-2, pp. 216223, 2005.

[85] F. Zhang, R. Xie, F. M. Munoz, S. S. Lau, and T. J. Monks, "PARP-1 hyperactivation and reciprocal elevations in intracellular Ca2+ during ROS-induced nonapoptotic cell death," Toxicological Sciences, vol. 140, no. 1, pp. 118-134, 2014.

[86] J. Camacho-Pereira, M. G. Tarragó, C. C. S. Chini et al., "CD38 dictates age-related NAD decline and mitochondrial dysfunction through an SIRT3-dependent mechanism," Cell Metabolism, vol. 23, no. 6, pp. 1127-1139, 2016.

[87] D. W. Frederick, E. Loro, L. Liu et al., "Loss of NAD homeostasis leads to progressive and reversible degeneration of skeletal muscle," Cell Metabolism, vol. 24, no. 2, pp. 269-282, 2016.

[88] L. Mouchiroud, R. H. Houtkooper, N. Moullan et al., "The $\mathrm{NAD}+$ /sirtuin pathway modulates longevity through activation of mitochondrial UPR and FOXO signaling," Cell, vol. 154, no. 2, pp. 430-441, 2013.

[89] R. L. Veech, R. Guynn, and D. Veloso, "The time-course of the effects of ethanol on the redox and phosphorylation states of rat liver," The Biochemical Journal, vol. 127, no. 2, pp. 387397, 1972.

[90] D. H. Williamson, P. Lund, and H. A. Krebs, "The redox state of free nicotinamide-adenine dinucleotide in the cytoplasm and mitochondria of rat liver," The Biochemical Journal, vol. 103, no. 2, pp. 514-527, 1967.

[91] C. C. Alano, W. Ying, and R. A. Swanson, "Poly(ADP-ribose) polymerase-1-mediated cell death in astrocytes requires NAD + depletion and mitochondrial permeability transition," The Journal of Biological Chemistry, vol. 279, no. 18, pp. 1889518902, 2004.

[92] P. Bai, C. Cantó, H. Oudart et al., "PARP-1 inhibition increases mitochondrial metabolism through SIRT1 activation," Cell Metabolism, vol. 13, no. 4, pp. 461-468, 2011.

[93] M. Pittelli, R. Felici, V. Pitozzi et al., "Pharmacological effects of exogenous NAD on mitochondrial bioenergetics, DNA repair, and apoptosis," Molecular Pharmacology, vol. 80, no. 6, pp. 1136-1146, 2011.

[94] S. Weinhouse, "The Warburg hypothesis fifty years later," Zeitschrift für Krebsforschung und Klinische Onkologie, vol. 87, pp. 115-126, 1976.

[95] V. R. Fantin, J. St-Pierre, and P. Leder, "Attenuation of LDHA expression uncovers a link between glycolysis, mitochondrial physiology, and tumor maintenance," Cancer Cell, vol. 9, no. 6, pp. 425-434, 2006.

[96] R. Moreno-Sánchez, S. Rodríguez-Enríquez, A. MarínHernández, and E. Saavedra, "Energy metabolism in tumor cells," The FEBS Journal, vol. 274, no. 6, pp. 1393-1418, 2007.
[97] M. G. Vander Heiden, L. C. Cantley, and C. B. Thompson, "Understanding the Warburg effect: the metabolic requirements of cell proliferation," Science, vol. 324, no. 5930, pp. 1029-1033, 2009.

[98] S. Gottschalk, N. Anderson, C. Hainz, S. G. Eckhardt, and N. J. Serkova, "Imatinib (STI571)-mediated changes in glucose metabolism in human leukemia BCR-ABL-positive cells," Clinical Cancer Research, vol. 10, no. 19, pp. 66616668, 2004.

[99] H. R. Christofk, M. G. Vander Heiden, M. H. Harris et al., "The M2 splice isoform of pyruvate kinase is important for cancer metabolism and tumour growth," Nature, vol. 452, no. 7184, pp. 230-233, 2008.

[100] K. B. Nolop, C. G. Rhodes, L. H. Brudin et al., "Glucose utilization in vivo by human pulmonary neoplasms," Cancer, vol. 60, no. 11, pp. 2682-2689, 1987.

[101] A. Szent-Györgyi, “The living state and cancer,” Proceedings of the National Academy of Sciences, vol. 74, no. 7, pp. 2844-2847, 1977.

[102] F. Jacob, D. Perrin, C. Sánchez, J. Monod, and S. Edelstein, "The operon: a group of genes with expression coordinated by an operator," Comptes rendus hebdomadaires des seances de l'Academie des sciences, vol. 250, 1960.

[103] W. H. Koppenol, P. L. Bounds, and C. V. Dang, "Otto Warburg's contributions to current concepts of cancer metabolism," Nature Reviews. Cancer, vol. 11, no. 5, pp. 325-337, 2011.

[104] J. van den Brink, A. B. Canelas, W. M. van Gulik et al., "Dynamics of glycolytic regulation during adaptation of Saccharomyces cerevisiae to fermentative metabolism," Applied and Environmental Microbiology, vol. 74, no. 18, pp. 5710-5723, 2008.

[105] D. S. Izyumov, A. V. Avetisyan, O. Y. Pletjushkina et al., "“Wages of fear": transient threefold decrease in intracellular ATP level imposes apoptosis," Biochimica et Biophysica Acta (BBA) - Bioenergetics, vol. 1658, no. 1-2, pp. 141-147, 2004.

[106] K. A. Brand and U. Hermfisse, "Aerobic glycolysis by proliferating cells: a protective strategy against reactive oxygen species," The FASEB Journal, vol. 11, no. 5, pp. 388-395, 1997.

[107] T. N. Seyfried, G. Yu, J. C. Maroon, and D. P. D’Agostino, "Press-pulse: a novel therapeutic strategy for the metabolic management of cancer," Nutrition \& Metabolism (London), vol. 14, no. 1, 2017.

[108] M. I. Amores-Sánchez and M. Á. Medina, "Glutamine, as a precursor of glutathione, and oxidative stress," Molecular Genetics and Metabolism, vol. 67, no. 2, pp. 100-105, 1999.

[109] B. Poljsak and I. Milisav, "The role of antioxidants in cancer, friends or foes?," Current Pharmaceutical Design, vol. 24, no. 44, pp. 5234-5244, 2019.

[110] U. Lang, R. S. Baker, G. Braems, M. Zygmunt, W. Künzel, and K. E. Clark, "Uterine blood flow-a determinant of fetal growth," European Journal of Obstetrics, Gynecology, and Reproductive Biology, vol. 110, Suppl 1, pp. S55-S61, 2003.

[111] J. M. Berg, J. L. Tymoczko, and L. Stryer, "Protein structure and function," Biochemistry, vol. 262, pp. 159-173, 2002.

[112] W. D. McArdle, F. I. Katch, and V. L. Katch, "Energy expenditure at rest and during physical activity," Essentials of Exercise Physiology, vol. 1, pp. 260-289, 2000.

[113] T. D. Noakes, "Physiological models to understand exercise fatigue and the adaptations that predict or enhance athletic 
performance," Scandinavian Journal of Medicine \& Science in Sports, vol. 10, no. 3, pp. 123-145, 2000.

[114] H.-S. Kim, K. Patel, K. Muldoon-Jacobs et al., "SIRT3 is a mitochondria-localized tumor suppressor required for maintenance of mitochondrial integrity and metabolism during stress," Cancer Cell, vol. 17, no. 1, pp. 41-52, 2010.

[115] L. W. S. Finley, A. Carracedo, J. Lee et al., "SIRT3 opposes reprogramming of cancer cell metabolism through HIF1 $\alpha$ destabilization," Cancer Cell, vol. 19, no. 3, pp. 416-428, 2011.

[116] E. L. Bell, B. M. Emerling, S. J. H. Ricoult, and L. Guarente, "SirT3 suppresses hypoxia inducible factor $1 \alpha$ and tumor growth by inhibiting mitochondrial ROS production," Oncogene, vol. 30, no. 26, pp. 2986-2996, 2011.

[117] B. T. Tan, C. Y. Park, L. E. Ailles, and I. L. Weissman, "The cancer stem cell hypothesis: a work in progress," Laboratory Investigation, vol. 86, no. 12, pp. 1203-1207, 2006.

[118] I. Alkatout and H. Kalthoff, "Tumor stem cells: how to define them and how to find them?," in Stem Cells, pp. 165-185, Springer, Netherlands, 2008.

[119] E. Passegue, C. H. M. Jamieson, L. E. Ailles, and I. L. Weissman, "Normal and leukemic hematopoiesis: are leukemias a stem cell disorder or a reacquisition of stem cell characteristics?," Proceedings of the National Academy of Sciences, vol. 100, Supplement 1, pp. 11842-11849, 2003.

[120] A. Prigione, B. Fauler, R. Lurz, H. Lehrach, and J. Adjaye, "The senescence-related mitochondrial/oxidative stress pathway is repressed in human induced pluripotent stem cells," Stem Cells, vol. 28, no. 4, pp. 721-733, 2010.

[121] S. Varum, A. S. Rodrigues, M. B. Moura et al., "Energy metabolism in human pluripotent stem cells and their differentiated counterparts," PLoS One, vol. 6, no. 6, 2011.

[122] A. Prigione, B. Lichtner, H. Kuhl et al., "Human iPSCs harbor homoplasmic and heteroplasmic mitochondrial DNA mutations while maintaining hESC-like metabolic reprogramming," Stem Cells, vol. 29, pp. 1338-1348, 2011.

[123] A. D. Panopoulos, O. Yanes, S. Ruiz et al., "The metabolome of induced pluripotent stem cells reveals metabolic changes occurring in somatic cell reprogramming," Cell Research, vol. 22, no. 1, pp. 168-177, 2012.

[124] A. Prigione and J. Adjaye, "Modulation of mitochondrial biogenesis and bioenergetic metabolism upon in vitro and in vivo differentiation of human ES and iPS cells," The International Journal of Developmental Biology, vol. 54, no. 11-12, pp. 1729-1741, 2010.

[125] J. M. Cuezva, M. Sánchez-Aragó, S. Sala, A. Blanco-Rivero, and Á. D. Ortega, "A message emerging from development: the repression of mitochondrial $\beta$-F1-ATPase expression in cancer," Journal of Bioenergetics and Biomembranes, vol. 39, no. 3, pp. 259-265, 2007.

[126] L. Sánchez-Cenizo, L. Formentini, M. Aldea et al., "Upregulation of the ATPase inhibitory factor 1 (IF1) of the mitochondrial $\mathrm{H}^{+}$-ATP synthase in human tumors mediates the metabolic shift of cancer cells to a Warburg phenotype," The Journal of Biological Chemistry, vol. 285, no. 33, pp. 25308-25313, 2010.

[127] M. Sánchez-Aragó, M. Chamorro, and J. M. Cuezva, “Selection of cancer cells with repressed mitochondria triggers colon cancer progression," Carcinogenesis, vol. 31, no. 4, pp. 567-576, 2010.

[128] R. Abu Dawud, K. Schreiber, D. Schomburg, and J. Adjaye, "Human embryonic stem cells and embryonal carcinoma cells have overlapping and distinct metabolic signatures," PLoS One, vol. 7, no. 6, 2012.

[129] A. V. Gudkov, K. V. Gurova, and E. A. Komarova, "Inflammation and p53: a tale of two stresses," Genes \& Cancer, vol. 2, no. 4, pp. 503-516, 2011.

[130] B. B. Aggarwal, S. Shishodia, S. K. Sandur, M. K. Pandey, and G. Sethi, "Inflammation and cancer: how hot is the link?," Biochemical Pharmacology, vol. 72, no. 11, pp. 1605-1621, 2006.

[131] A. Mantovani, P. Allavena, A. Sica, and F. Balkwill, "Cancerrelated inflammation,” Nature, vol. 454, no. 7203, pp. 436444, 2008.

[132] G. Müzes and F. Sipos, "Inflammasome, inflammation and cancer: an interrelated pathobiological triad," Current Drug Targets, vol. 16, no. 3, pp. 249-257, 2015.

[133] S. Khan, M. Jain, V. Mathur, and S. M. Feroz, "Chronic Inflammation and Cancer: Paradigm on Tumor Progression, Metastasis and Therapeutic Intervention," The Gulf Journal of Oncology, vol. 1, no. 20, pp. 86-93, 2016.

[134] G. Trinchieri, "Cancer and inflammation: an old intuition with rapidly evolving new concepts," Annual Review of Immunology, vol. 30, no. 1, pp. 677-706, 2012.

[135] S. Reuter, S. C. Gupta, M. M. Chaturvedi, and B. B. Aggarwal, "Oxidative stress, inflammation, and cancer: how are they linked?," Free Radical Biology \& Medicine, vol. 49, no. 11, pp. 1603-1616, 2010.

[136] T. P. Raposo, B. C. B. Beirão, L. Y. Pang, F. L. Queiroga, and D. J. Argyle, "Inflammation and cancer: till death tears them apart," Veterinary Journal, vol. 205, no. 2, pp. 161-174, 2015.

[137] A. R. Maiuri and H. M. O’Hagan, "Interplay between inflammation and epigenetic changes in cancer," Progress in Molecular Biology and Translational Science, vol. 144, pp. 69-117, 2016.

[138] L. M. Coussens and Z. Werb, "Inflammation and cancer," Nature, vol. 420, no. 6917, pp. 860-867, 2002.

[139] A. S. Adler, S. Sinha, T. L. A. Kawahara, J. Y. Zhang, E. Segal, and H. Y. Chang, "Motif module map reveals enforcement of aging by continual NF- B activity," Genes \& Development, vol. 21, no. 24, pp. 3244-3257, 2007.

[140] A. Salminen and K. Kaarniranta, "Genetics vs. entropy: longevity factors suppress the NF- $\kappa B$-driven entropic aging process," Ageing Research Reviews, vol. 9, no. 3, pp. 298-314, 2010.

[141] T. N. Seyfried, "Perspectives on brain tumor formation involving macrophages, glia, and neural stem cells," Perspectives in Biology and Medicine, vol. 44, no. 2, pp. 263-282, 2001.

[142] M. B. Schultz and D. A. Sinclair, "Why NAD + declines during aging: it's destroyed," Cell Metabolism, vol. 23, no. 6, pp. $965-966,2016$.

[143] M. Altmeyer and M. O. Hottiger, "Poly(ADP-ribose) polymerase 1 at the crossroad of metabolic stress and inflammation in aging," Aging, vol. 1, no. 5, pp. 458-469, 2009.

[144] D. Liu, R. Gharavi, M. Pitta, M. Gleichmann, and M. P. Mattson, "Nicotinamide prevents NAD+ depletion and protects neurons against excitotoxicity and cerebral ischemia: NAD+ consumption by SIRT1 may endanger energetically compromised neurons," Neuromolecular Medicine, vol. 11, no. 1, pp. 28-42, 2009.

[145] N. Braidy and R. Grant, "Kynurenine pathway metabolism and neuroinflammatory disease," Neural Regeneration Research, vol. 12, no. 1, pp. 39-42, 2017. 
[146] T. F. Liu and C. E. McCall, "Deacetylation by SIRT1 reprograms inflammation and cancer," Genes \& Cancer, vol. 4, no. 3-4, pp. 135-147, 2013.

[147] J. S. Smith, "Human Sir2 and the 'silencing' of p53 activity," Trends in Cell Biology, vol. 12, no. 9, pp. 404-406, 2002.

[148] P. Tucci, "Caloric restriction: is mammalian life extension linked to p53?," Aging, vol. 4, no. 8, pp. 525-534, 2012.

[149] R. Schwarcz and R. Pellicciari, "Manipulation of brain kynurenines: glial targets, neuronal effects, and clinical opportunities," The Journal of Pharmacology and Experimental Therapeutics, vol. 303, no. 1, pp. 1-10, 2002.

[150] K. G. Tirumurugaan, B. N. Kang, R. A. Panettieri, D. N. Foster, T. F. Walseth, and M. S. Kannan, "Regulation of the $\mathrm{cd} 38$ promoter in human airway smooth muscle cells by TNF- $\alpha$ and dexamethasone," Respiratory Research, vol. 9, no. 1, 2008.

[151] V. T. Vachharajani, T. Liu, X. Wang, J. J. Hoth, B. K. Yoza, and C. E. McCall, "Sirtuins link inflammation and metabolism," Journal of Immunology Research, vol. 2016, Article ID 8167273, 10 pages, 2016.

[152] P. A. Kramer, S. Ravi, B. Chacko, M. S. Johnson, and V. M. Darley-Usmar, "A review of the mitochondrial and glycolytic metabolism in human platelets and leukocytes: implications for their use as bioenergetic biomarkers," Redox Biology, vol. 2, pp. 206-210, 2014.

[153] J.-C. Rodríguez-Prados, P. G. Través, J. Cuenca et al., "Substrate fate in activated macrophages: a comparison between innate, classic, and alternative activation," Journal of Immunology, vol. 185, no. 1, pp. 605-614, 2010.

[154] L. A. J. O'Neill and D. G. Hardie, "Metabolism of inflammation limited by AMPK and pseudo-starvation," Nature, vol. 493, no. 7432, pp. 346-355, 2013.

[155] G. M. Tannahill, A. M. Curtis, J. Adamik et al., "Succinate is an inflammatory signal that induces IL- $1 \beta$ through HIF- $1 \alpha$," Nature, vol. 496, no. 7444, pp. 238-242, 2013.

[156] Y. Ovadya, T. Landsberger, H. Leins et al., "Impaired immune surveillance accelerates accumulation of senescent cells and aging," Nature Communications, vol. 9, no. 1, p. 5435, 2018.

[157] H. D. Halicka, B. Ardelt, X. Li, M. M. Melamed, and Z. Darzynkiewicz, "2-Deoxy-D-glucose enhances sensitivity of human histiocytic lymphoma U937 cells to apoptosis induced by tumor necrosis factor," Cancer Research, vol. 55, 1995.

[158] J. F. H. Geschwind, Y. H. Ko, M. S. Torbenson, C. Magee, and P. L. Pedersen, "Novel therapy for liver cancer: direct intraarterial injection of a potent inhibitor of ATP production," Cancer Research, vol. 62, no. 14, pp. 3909-3913, 2002.

[159] Y. H. Ko, B. L. Smith, Y. Wang et al., "Advanced cancers: eradication in all cases using 3-bromopyruvate therapy to deplete ATP," Biochemical and Biophysical Research Communications, vol. 324, no. 1, pp. 269-275, 2004.

[160] N. C. Denko, "Hypoxia, HIF1 and glucose metabolism in the solid tumour," Nature Reviews. Cancer, vol. 8, no. 9, pp. 705713, 2008.

[161] M. López-Lázaro, "The Warburg effect: why and how do cancer cells activate glycolysis in the presence of oxygen?," Anti-Cancer Agents in Medicinal Chemistry, vol. 8, no. 3, pp. 305-312, 2008.

[162] S. Rodríguez-Enríquez, A. Marín-Hernández, J. C. GallardoPérez, L. Carreño-Fuentes, and R. Moreno-Sánchez, “Target- ing of cancer energy metabolism," Molecular Nutrition \& Food Research, vol. 53, no. 1, pp. 29-48, 2009.

[163] X. Cao, L. Fang, S. Gibbs et al., "Glucose uptake inhibitor sensitizes cancer cells to daunorubicin and overcomes drug resistance in hypoxia," Cancer Chemotherapy and Pharmacology, vol. 59, no. 4, pp. 495-505, 2007.

[164] T. J. Schulz, R. Thierbach, A. Voigt et al., "Induction of oxidative metabolism by mitochondrial frataxin inhibits cancer growth," The Journal of Biological Chemistry, vol. 281, no. 2, pp. 977-981, 2006.

[165] M. Ristow, M. F. Pfister, A. J. Yee et al., "Frataxin activates mitochondrial energy conversion and oxidative phosphorylation," Proceedings of the National Academy of Sciences, vol. 97, no. 22, pp. 12239-12243, 2000.

[166] Y. Zhao, H. Liu, Z. Liu et al., "Overcoming trastuzumab resistance in breast cancer by targeting dysregulated glucose metabolism," Cancer Research, vol. 71, no. 13, pp. 45854597, 2011.

[167] R. C. Sun, P. G. Board, and A. C. Blackburn, "Targeting metabolism with arsenic trioxide and dichloroacetate in breast cancer cells," Molecular Cancer, vol. 10, no. 1, 2011.

[168] E. D. Michelakis, L. Webster, and J. R. Mackey, "Dichloroacetate (DCA) as a potential metabolic-targeting therapy for cancer," British Journal of Cancer, vol. 99, no. 7, pp. 989-994, 2008.

[169] A. Kumar, S. Kant, and S. M. Singh, "Novel molecular mechanisms of antitumor action of dichloroacetate against $\mathrm{T}$ cell lymphoma: implication of altered glucose metabolism, $\mathrm{pH}$ homeostasis and cell survival regulation," Chemico-Biological Interactions, vol. 199, no. 1, pp. 29-37, 2012.

[170] G. M. Saed, N. M. Fletcher, Z. L. Jiang, H. M. Abu-Soud, and M. P. Diamond, "Dichloroacetate induces apoptosis of epithelial ovarian cancer cells through a mechanism involving modulation of oxidative stress," Reproductive Sciences, vol. 18, no. 12, pp. 1253-1261, 2011.

[171] P. Shen, T. Jiang, H. Lu, H. Han, and R. Luo, "Combination of poly I:C and arsenic trioxide triggers apoptosis synergistically via activation of TLR3 and mitochondrial pathways in hepatocellular carcinoma cells," Cell Biology International, vol. 35, no. 8, pp. 803-810, 2011.

[172] W. Wang, M. Adachi, R. Zhang, J. Zhou, and D. Zhu, "A novel combination therapy with arsenic trioxide and parthenolide against pancreatic cancer cells," Pancreas, vol. 38, no. 4, pp. e114-e123, 2009.

[173] C. Cantó and J. Auwerx, "Interference between PARPs and SIRT1: a novel approach to healthy ageing?" Aging, vol. 3, no. 5, pp. 543-547, 2011.

[174] T. Finkel, C.-X. Deng, and R. Mostoslavsky, "Recent progress in the biology and physiology of sirtuins," Nature, vol. 460, no. 7255, pp. 587-591, 2009.

[175] L. W. S. Finley and M. C. Haigis, "Metabolic regulation by SIRT3: implications for tumorigenesis," Trends in Molecular Medicine, vol. 18, no. 9, pp. 516-523, 2012.

[176] J.-H. Lim, Y. M. Lee, Y. S. Chun, J. Chen, J. E. Kim, and J. W. Park, "Sirtuin 1 modulates cellular responses to hypoxia by deacetylating hypoxia-inducible factor $1 \alpha$," Molecular Cell, vol. 38, no. 6, pp. 864-878, 2010.

[177] A. R. Hipkiss, "Energy metabolism, altered proteins, sirtuins and ageing: converging mechanisms?," Biogerontology, vol. 9, no. 1, pp. 49-55, 2008. 
[178] K. C. Morris, H. W. Lin, J. W. Thompson, and M. A. PerezPinzon, "Pathways for ischemic cytoprotection: role of sirtuins in caloric restriction, resveratrol, and ischemic preconditioning," Journal of Cerebral Blood Flow and Metabolism, vol. 31, no. 4, pp. 1003-1019, 2011.

[179] E. Morselli, M. C. Maiuri, M. Markaki et al., "Caloric restriction and resveratrol promote longevity through the Sirtuin-1dependent induction of autophagy," Cell Death \& Disease, vol. 1, no. 1, pp. e10-e10, 2010.

[180] T. von Lukowicz, P. O. Hassa, C. Lohmann et al., "PARP1 is required for adhesion molecule expression in atherogenesis," Cardiovascular Research, vol. 78, no. 1, pp. 158-166, 2008.

[181] P. Jagtap and C. Szabó, "Poly(ADP-ribose) polymerase and the therapeutic effects of its inhibitors," Nature Reviews. Drug Discovery, vol. 4, no. 5, pp. 421-440, 2005.

[182] R. Kiefmann, K. Heckel, M. Doerger et al., "Role of PARP on iNOS pathway during endotoxin-induced acute lung injury," Intensive Care Medicine, vol. 30, no. 7, 2004.

[183] N. Curtin, "PARP inhibitors for anticancer therapy," Biochemical Society Transactions, vol. 42, no. 1, pp. 82-88, 2014.

[184] C. D. Haffner, J. D. Becherer, E. E. Boros et al., "Discovery, synthesis, and biological evaluation of thiazoloquin(az)olin(on)es as potent CD38 inhibitors," Journal of Medicinal Chemistry, vol. 58, no. 8, pp. 3548-3571, 2015.

[185] J. Gerdts, E. J. Brace, Y. Sasaki, A. DiAntonio, and J. Milbrandt, "SARM1 activation triggers axon degeneration locally via NAD+ destruction," Science, vol. 348, no. 6233, pp. 453-457, 2015.

[186] B. Poljsak, T. N. Seyfried, D. P. D’Agostino, A. M. Poff, and I. Milisav, Reduction of Sporadic Malignancies by Stimulation of Cellular Repair Systems and by Targeting Cellular Energy Metabolism, Nova Science Publisher, 2017.

[187] R. S. Sohal and R. Weindruch, "Oxidative stress, caloric restriction, and aging," Science, vol. 273, no. 5271, pp. 5963, 1996.

[188] C. B. Harris, W. Chowanadisai, D. O. Mishchuk, M. A. Satre, C. M. Slupsky, and R. B. Rucker, "Dietary pyrroloquinoline quinone (PQQ) alters indicators of inflammation and mitochondrial-related metabolism in human subjects," The Journal of Nutritional Biochemistry, vol. 24, no. 12, pp. 2076-2084, 2013.

[189] W. Chowanadisai, K. A. Bauerly, E. Tchaparian, A. Wong, G. A. Cortopassi, and R. B. Rucker, "Pyrroloquinoline quinone stimulates mitochondrial biogenesis through cAMP response element-binding protein phosphorylation and increased PGC- $1 \alpha$ expression," The Journal of Biological Chemistry, vol. 285, no. 1, pp. 142-152, 2010.

[190] L. E. B. Stuhr, V. V. Iversen, O. Straume, B. O. Mæhle, and R. K. Reed, "Hyperbaric oxygen alone or combined with 5FU attenuates growth of DMBA-induced rat mammary tumors," Cancer Letters, vol. 210, no. 1, pp. 35-40, 2004.

[191] J. Daruwalla and C. Christophi, "Hyperbaric oxygen therapy for malignancy: a review," World Journal of Surgery, vol. 30, no. 12, pp. 2112-2131, 2006.

[192] E. Palzur, M. Zaaroor, E. Vlodavsky, F. Milman, and J. F. Soustiel, "Neuroprotective effect of hyperbaric oxygen therapy in brain injury is mediated by preservation of mitochondrial membrane properties," Brain Research, vol. 1221, pp. 126-133, 2008.

[193] A. M. Poff, C. Ari, T. N. Seyfried, and D. P. D’Agostino, “The ketogenic diet and hyperbaric oxygen therapy prolong sur- vival in mice with systemic metastatic cancer," PLoS One, vol. 8, no. 6, p. e65522, 2013.

[194] S. Zhou, M. Abdouh, V. Arena, M. Arena, and G. O. Arena, "Reprogramming malignant cancer cells toward a benign phenotype following exposure to human embryonic stem cell microenvironment," PLoS One, vol. 12, no. 1, p. e0169899, 2017.

[195] C. M. Nelson and C. S. Chen, "Cell-cell signaling by direct contact increases cell proliferation via a PI3K-dependent signal," FEBS Letters, vol. 514, no. 2-3, pp. 238-242, 2002.

[196] B. I. Shraiman, "Mechanical feedback as a possible regulator of tissue growth," Proceedings of the National Academy of Sciences of the United States of America, vol. 102, no. 9, pp. 3318-3323, 2005.

[197] A. M. Poff, C. Ari, P. Arnold, T. N. Seyfried, and D. P. D'Agostino, "Ketone supplementation decreases tumor cell viability and prolongs survival of mice with metastatic cancer," International Journal of Cancer, vol. 135, no. 7, pp. 1711-1720, 2014.

[198] B. A. Magee, N. Potezny, A. M. Rofe, and R. A. Conyers, "The inhibition of malignant cell growth by ketone bodies," The Australian Journal of Experimental Biology and Medical Science, vol. 57, no. 5, pp. 529-539, 1979.

[199] G. D. Maurer, D. P. Brucker, O. Bähr et al., "Differential utilization of ketone bodies by neurons and glioma cell lines: a rationale for ketogenic diet as experimental glioma therapy," BMC Cancer, vol. 11, no. 1, 2011.

[200] R. Skinner, A. Trujillo, X. Ma, and E. A. Beierle, "Ketone bodies inhibit the viability of human neuroblastoma cells," Journal of Pediatric Surgery, vol. 44, no. 1, pp. 212-216, 2009.

[201] M. Yuneva, "Finding an "Achilles' heel” of cancer: the role of glucose and glutamine metabolism in the survival of transformed cells," Cell Cycle, vol. 7, no. 14, pp. 2083-2089, 2008.

[202] H. W. Dion, S. A. Fusari, Z. L. Jakubowski, J. G. Zora, and Q. R. Bartz, "6-Diazo-5-oxo-L-norleucine, a new tumorinhibitory substance. II. ${ }^{1}$ Isolation and characterization ${ }^{2}$," Journal of the American Chemical Society, vol. 78, no. 13, pp. 3075-3077, 1956.

[203] D. L. Kisner, R. Catane, and F. M. Muggia, "The rediscovery of DON (6-diazo-5-oxo-L-norleucine)," in Recent Results in Cancer Research, pp. 258-263, Springer, Berlin, Heidelberg, 1980.

[204] K. Lemberg, Y. Wu, J. Alt et al., “Abstract 3524: novel prodrugs of the glutamine antagonist 6-diazo-5-oxo-norleucine (DON) as treatment for malignant peripheral nerve sheath tumor," in Molecular and Cellular Biology/Genetics, pp. 3524-3524, American Association for Cancer Research, 2018.

[205] P. Mukherjee, Z. M. Augur, M. Li et al., "Therapeutic benefit of combining calorie-restricted ketogenic diet and glutamine targeting in late-stage experimental glioblastoma," Communications Biology, vol. 2, no. 1, 2019.

[206] M.-H. Kim and H. Kim, "The roles of glutamine in the intestine and its implication in intestinal diseases," International Journal of Molecular Sciences, vol. 18, no. 5, p. 1051, 2017.

[207] M. S. İyikesici, A. K. Slocum, A. Slocum, F. B. Berkarda, M. Kalamian, and T. N. Seyfried, "Efficacy of metabolically supported chemotherapy combined with ketogenic diet, hyperthermia, and hyperbaric oxygen therapy for stage IV triple-negative breast cancer," Cureus, vol. 9, 2017. 
[208] J. M. M. Evans, L. A. Donnelly, A. M. Emslie-Smith, D. R. Alessi, and A. D. Morris, "Metformin and reduced risk of cancer in diabetic patients," BMJ, vol. 330, no. 7503, pp. 13041305, 2005.

[209] J. Marsh, P. Mukherjee, and T. N. Seyfried, “Akt-dependent proapoptotic effects of dietary restriction on late-stage management of a phosphatase and tensin homologue/tuberous sclerosis complex 2-deficient mouse astrocytoma," Clinical Cancer Research, vol. 14, no. 23, pp. 7751-7762, 2008.

[210] T. N. Seyfried, T. M. Sanderson, M. M. El-Abbadi, R. McGowan, and P. Mukherjee, "Role of glucose and ketone bodies in the metabolic control of experimental brain cancer," British Journal of Cancer, vol. 89, no. 7, pp. 13751382, 2003.

[211] D. G. Hardie, "Adenosine monophosphate-activated protein kinase: a central regulator of metabolism with roles in diabetes, cancer, and viral infection," Cold Spring Harbor Symposia on Quantitative Biology, vol. 76, no. 0, pp. 155-164, 2011.

[212] W. W. Winder, "Energy-sensing and signaling by AMPactivated protein kinase in skeletal muscle," Journal of Applied Physiology, vol. 91, no. 3, pp. 1017-1028, 2001.

[213] M. Suter, U. Riek, R. Tuerk, U. Schlattner, T. Wallimann, and D. Neumann, "Dissecting the role of 5 '-AMP for allosteric stimulation, activation, and deactivation of AMP-activated protein kinase," The Journal of Biological Chemistry, vol. 281, no. 43, pp. 32207-32216, 2006.

[214] J. M. Corton, J. G. Gillespie, S. A. Hawley, and D. G. Hardie, "5-Aminoimidazole-4-carboxamide ribonucleoside. A specific method for activating AMP-activated protein kinase in intact cells?," European Journal of Biochemistry, vol. 229, no. 2, pp. 558-565, 1995.

[215] D. Chen, S. Banerjee, Q. C. Cui, D. Kong, F. H. Sarkar, and Q. P. Dou, "Activation of AMP-activated protein kinase by $3,3^{\prime}$-diindolylmethane (DIM) is associated with human prostate cancer cell death in vitro and in vivo," PLoS One, vol. 7, no. $10,2012$.

[216] B. Faubert, G. Boily, S. Izreig et al., "AMPK is a negative regulator of the Warburg effect and suppresses tumor growth in vivo," Cell Metabolism, vol. 17, no. 1, pp. 113124, 2013.

[217] S. B. Jørgensen, E. A. Richter, and J. F. P. Wojtaszewski, "Role of AMPK in skeletal muscle metabolic regulation and adaptation in relation to exercise," The Journal of Physiology, vol. 574, no. 1, pp. 17-31, 2006.

[218] A. Philp, L. M. Burke, and K. Baar, "Altering endogenous carbohydrate availability to support training adaptations," Nestle Nutrition Institute Workshop Series, vol. 69, pp. 19-31, 2011.

[219] A. Thirupathi and Y.-Z. Chang, "Role of AMPK and its molecular intermediates in subjugating cancer survival mechanism," Life Sciences, vol. 227, pp. 30-38, 2019.

[220] D. M. Gwinn, D. B. Shackelford, D. F. Egan et al., "AMPK phosphorylation of raptor mediates a metabolic checkpoint," Molecular Cell, vol. 30, no. 2, pp. 214-226, 2008.

[221] I. Milisav, B. Poljsak, and D. Suput, "Adaptive response, evidence of cross-resistance and its potential clinical use," International Journal of Molecular Sciences, vol. 13, no. 9, pp. 10771-10806, 2012.

[222] N. Hay and N. Sonenberg, "Upstream and downstream of mTOR," Genes \& Development, vol. 18, no. 16, pp. 19261945, 2004
[223] C. S. Beevers, F. Li, L. Liu, and S. Huang, "Curcumin inhibits the mammalian target of rapamycin-mediated signaling pathways in cancer cells," International Journal of Cancer, vol. 119, no. 4, pp. 757-764, 2006.

[224] R. J. DeBerardinis and N. S. Chandel, "Fundamentals of cancer metabolism," Science Advances, vol. 2, no. 5, p. e1600200, 2016.

[225] T. L. Yuan and L. C. Cantley, "PI3K pathway alterations in cancer: variations on a theme," Oncogene, vol. 27, no. 41, pp. 5497-5510, 2008.

[226] K. Inoki, J. Kim, and K.-L. Guan, "AMPK and mTOR in cellular energy homeostasis and drug targets," Annual Review of Pharmacology and Toxicology, vol. 52, no. 1, pp. 381-400, 2012.

[227] V. D. Longo and S. Panda, "Fasting, circadian rhythms, and time-restricted feeding in healthy lifespan," Cell Metabolism, vol. 23, no. 6, pp. 1048-1059, 2016.

[228] K. R. Zahid, M. Su, A. R. R. Khan, S. Han, G. Deming, and U. Raza, "Systems biology based meth-miRNA-mRNA regulatory network identifies metabolic imbalance and hyperactive cell cycle signaling involved in hepatocellular carcinoma onset and progression," Cancer Cell International, vol. 19, no. $1,2019$.

[229] D. G. Ryan, M. P. Murphy, C. Frezza et al., "Coupling Krebs cycle metabolites to signalling in immunity and cancer," Nature Metabolism, vol. 1, no. 1, pp. 16-33, 2019.

[230] Y.-H. Xu, Q. Q. Song, C. Li et al., "Bouchardatine suppresses rectal cancer in mice by disrupting its metabolic pathways via activating the SIRT1-PGC- $1 \alpha$-UCP2 axis," European Journal of Pharmacology, vol. 854, pp. 328-337, 2019.

[231] M. Weinert, A. Millet, E. A. Jonas, and K. N. Alavian, "The mitochondrial metabolic function of $D J-1$ is modulated by 14-3-3ß," The FASEB Journal, vol. 33, no. 8, pp. 8925-8934, 2019.

[232] R. H. Xu, H. Pelicano, Y. Zhou et al., "Inhibition of glycolysis in cancer cells: a novel strategy to overcome drug resistance associated with mitochondrial respiratory defect and hypoxia," Cancer Research, vol. 65, no. 2, pp. 613-621, 2005.

[233] S. Brandhorst and V. D. Longo, "Fasting and caloric restriction in cancer prevention and treatment," in Recent results in cancer research, vol. 207, pp. 241-266, Springer, 2016.

[234] S. Brandhorst, E. Harputlugil, J. R. Mitchell, and V. D. Longo, "Protective effects of short-term dietary restriction in surgical stress and chemotherapy," Ageing Research Reviews, vol. 39, pp. 68-77, 2017.

[235] A. Nencioni, I. Caffa, S. Cortellino, and V. D. Longo, "Fasting and cancer: molecular mechanisms and clinical application," Nature Reviews Cancer, vol. 18, no. 11, pp. 707-719, 2018. 


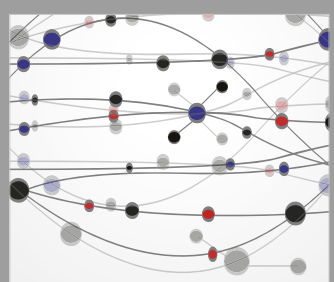

The Scientific World Journal
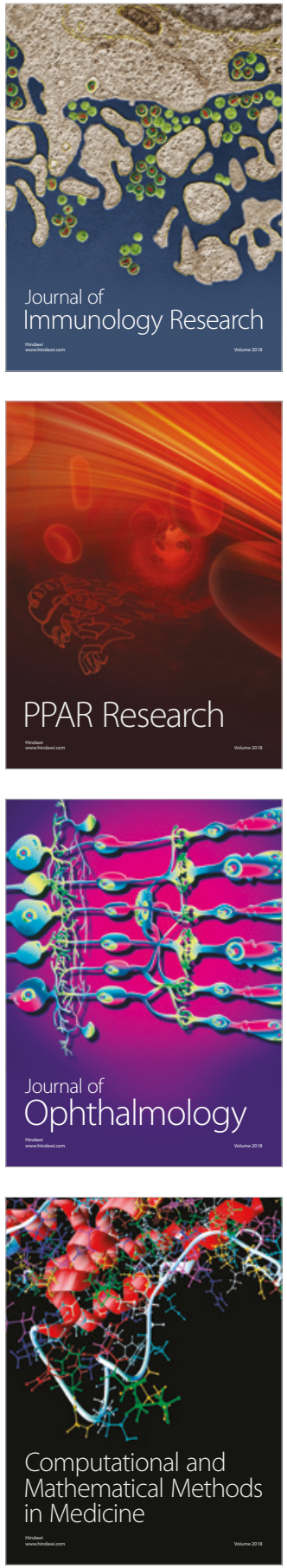

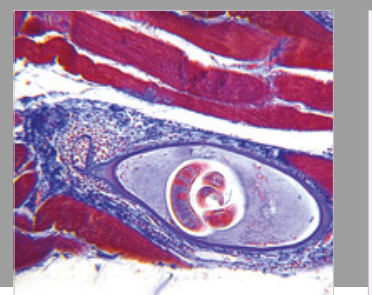

Gastroenterology Research and Practice

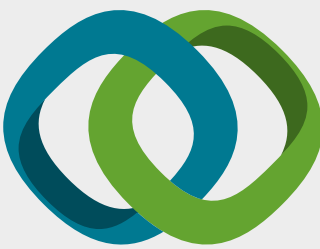

\section{Hindawi}

Submit your manuscripts at

www.hindawi.com
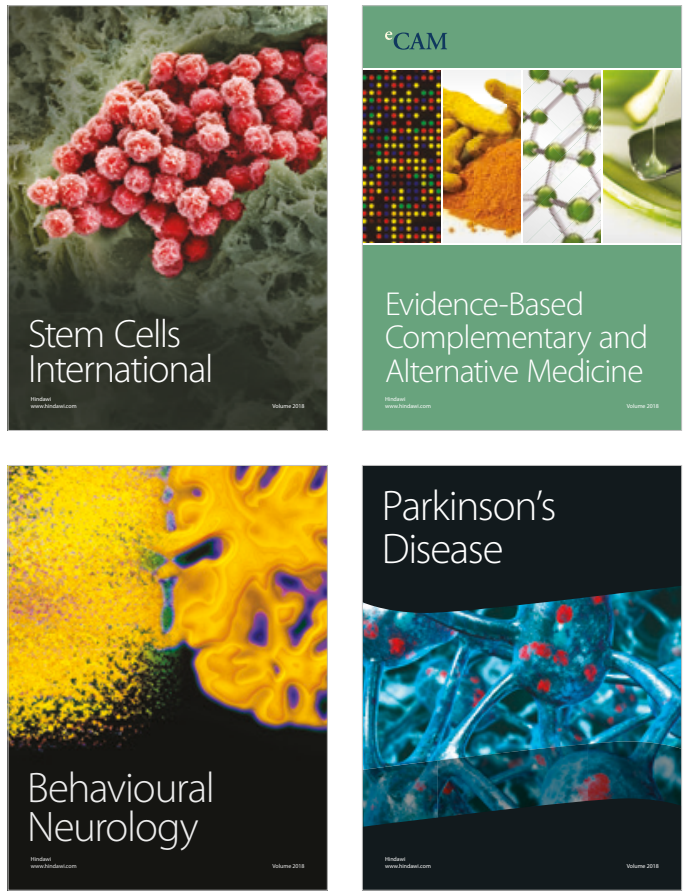

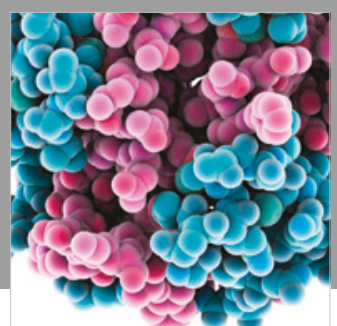

ournal of

Diabetes Research

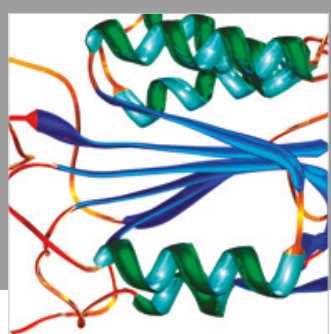

Disease Markers
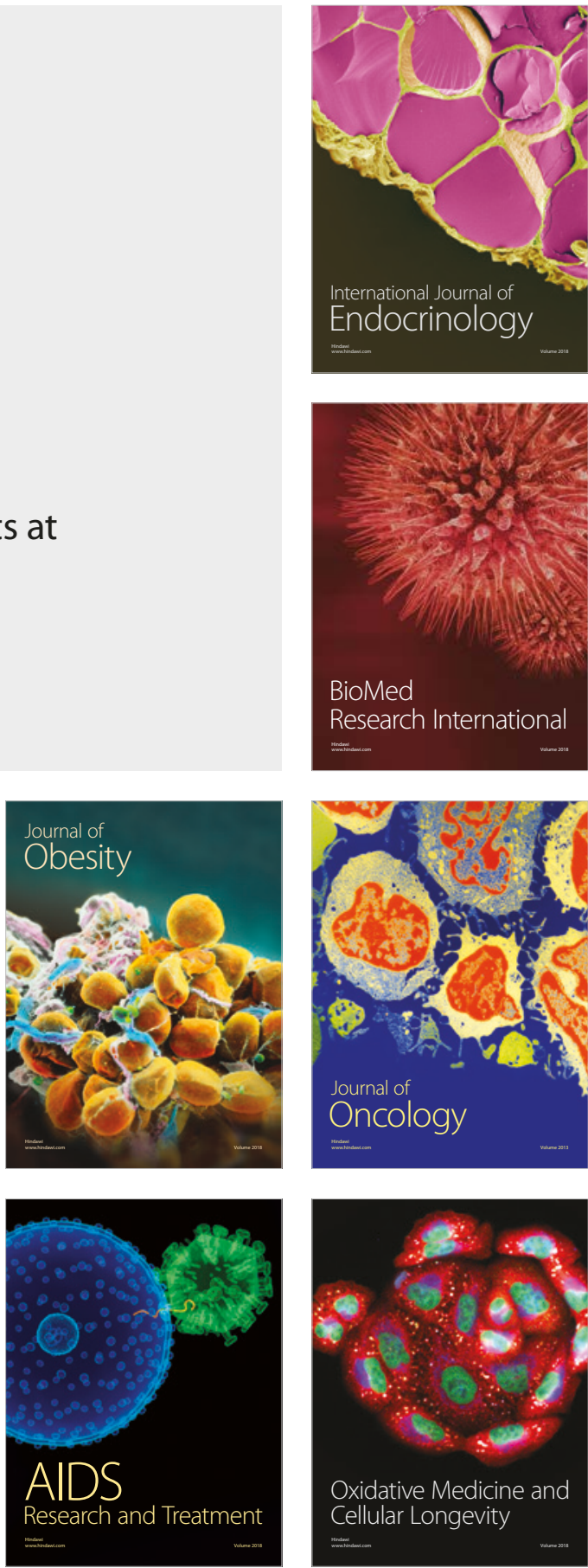